\title{
THE INFLUENCE OF CLINICAL TERMINOLOGY ON SELF-EFFICACY FOR VOICE
}

by

\author{
Amanda I Gillespie \\ B.S., New York University, 2003 \\ Submitted to the Graduate Faculty of \\ Communication Sciences and Disorders in partial fulfillment \\ of the requirements for the degree of \\ Master of Science
}

University of Pittsburgh

2005 


\section{UNIVERSITY OF PITTSBURGH}

\section{SCHOOL OF HEALTH AND REHABILITATION SCIENCES}

This thesis was presented

by

\section{Amanda I Gillespie, B.S., CFY}

It was defended on

August 17, 2005

and approved by

Christine Dollaghan, PhD., Communication Sciences and Disorders

William Klein, PhD., Health Psychology

Thesis Advisor: Katherine Verdolini, PhD., Communication Sciences and Disorders 


\title{
THE INFLUENCE OF CLINICAL TERMINOLOGY ON SELF-EFFICACY FOR VOICE
}

\author{
Amanda I Gillespie, B.S. - CFY \\ University of Pittsburgh, 2005
}

\begin{abstract}
$\underline{\text { Abstract }}$
The present study sought (1) to determine if any evidence could be found of an influence of clinical language on self-efficacy for voice in adults with voice problems; and (2) to determine the number of subjects that would be required to undertake future large-scale study around this question, if warranted, based on effect sizes determined in the present investigation. The study's relevance has to do with prior concerns raised in the literature that common clinical language in voice care—specifically language indicating vocal "abuse and misuse" as causal factors in selected voice disorders--has potential to harm self-efficacy for voice, which in turn may compromise patient compliance with treatment and thus clinical outcome (Verdolini, 1999). Fourteen teachers with self-reported voice disorders of unknown etiology were recruited as participants. Subjects were randomly assigned to one of two 15-min standardized, videotaped educational exposures by an unbiased clinician who was unaware of the experimental questions. One exposure described the origins of common voice problems in teachers in terms of vocal "abuse/misuse" $(\mathrm{N}=7)$. The other exposure described the
\end{abstract}


problems in terms of "phonotraumatic behaviors and muscular tension" $(\mathrm{N}=7)$. Before and immediately after exposures, subjects completed a visual analogue scale Voice SelfEfficacy Questionnaire that was specially designed for the study, that assessed situationneutral self-efficacy for voice. Psychometric evaluation of the tool indicated strong intrarater and test-retest reliability ( $r \geq$. 99; $r \geq .78$ respectively). The groups were also found to have no significant differences between them at the pre-test level, thus showing that amount of change on the post-test Voice Self-Efficacy Questionnaire were not influenced by individual subject differences on the pre-test. More conceptually interesting, binomial tests indicated that the majority of responses to self-efficacy questions reliably increased pre- to post exposure in the "phonotrauma/muscle tension" (20/28 responses; $p<.05)$, whereas no reliable change in scores was seen in the "abuse/misuse” group (11/28 responses increased; non-significant). A Chi-Square test was conducted, and as with the binomial test, found a statistical difference between the 11 increased/28 possible selfefficacy responses of the "abuse/misuse” group, and the 20/28 increased self-efficacy responses of the "phonotrauma" group to the $<.05$ level. Results provide preliminary support for the hypothesis that clinical exposure to "abuse/misuse" language may harm patients' self-efficacy for voice, not necessarily by decreasing pre-exposure self-efficacy but by compromising increases in self-efficacy that may normally be expected with patient education, as reported for other domains. The issue of self-efficacy for voice should be pursued in larger-scale studies in other laboratories. Effect sizes based on the present data indicated that at least 20 subjects per group ( $\mathrm{N}=40$ total) would be required to assess the effects of the noted terminology on voice-related self-efficacy shifts parametrically, using a similar experimental design. 


\section{TABLE OF CONTENTS}

I. INTRODUCTION 1

a. Voice Disorders: causes, effects on quality of life, and relevance of patient compliance in treatment

b. Factors influencing compliance with healthcare directives 5

$\begin{array}{ll}\text { c. Factors affecting self-efficacy } & 7\end{array}$

d. Gaps in the literature and issues to address 9

e. Experimental questions and hypothesis 10

II. METHODS 11

a. Participants 11

b. Procedures 12

c. Materials 13

i. Video presentation materials 13

ii. Self-efficacy measurement scale $\quad 15$

$\begin{array}{ll}\text { d. Data reduction } & 17\end{array}$

e. Statistical analysis 18

i. Reliability and internal consistency 18

ii. Experimental questions 18

$\begin{array}{ll}\text { III. } & 19\end{array}$

a. Properties of the Voice Self-Efficacy Questionnaire 19

i. Pre-Test Group Similarity 19

ii. Reliability 19

iii. Internal Consistency 20

b. Effect on clinical language on self-efficacy for voice 20

c. Power analysis 23

$\begin{array}{ll} & 23\end{array}$

APPENDIX A. Text for Abuse/Misuse Condition 47

APPENDIX B. Text for Phonotrauma/Muscle Tension Condition 52

BIBLIOGRAPHY 26 


\section{LIST OF TABLES}

1. Voice Self-Efficacy Questionnaire 35

2. Results of t-tests comparing groups on pretest items 36

3. Intra-rater Reliability. (Pearson $r$ and Interclass Correlation.) 39

4. Paired Samples T-Test analyzing intra-rater differences. 40

5. Test-Retest Reliability Raw Data 41

6. Intra-subject (Test-Retest) Reliability. (Pearson Correlation $r$ and Intraclass

Correlation, ICC). 42

7. Pearson Correlations between Responses to All Questions, and Significance

Levels, based on Pre-Test. 43

8. Individual Data: Pre- and Post-Exposure Responses to the Voice Self-Efficacy

Questionnaire (in mm). 44

9. Results of a T-test to compare groups on pre to post-test change. 46 


\section{LIST OF FIGURES}

1. Scatterplot Distribution of Pre-Test Similarity 
Preface.

\section{Acknowledgements}

This study was conducted as a master's thesis by the first author, under the guidance of the second author. The work was supported by the University of Pittsburgh's School of Health and Rehabilitation Sciences’ student research grant to the first author, and Grant R01 DC005643 from the National Institute on Deafness and Other Communication Disorders, to the second author. The authors would like to acknowledge the valuable assistance of Dr. Elaine Rubenstein for statistical consulting. The author would also like to acknowledge the support of Dr. Jackie Gartner-Schmidt, Dr. Christine Dollaghan, and Dr. William Klein. 
The Influence of Clinical Terminology on Self-Efficacy for Voice

\section{INTRODUCTION}

Clinicians and scientists involved with care of the voice are well aware that voice problems are among the most common communication disorders across the lifespan. An estimated 3-9\% of individuals in the United States have a voice disorder at any given moment in time (Ramig \& Verdolini, 1998). The causes of voice disorders are varied, however, a general consensus is that phonogenic voice problems are among the most common (e.g. Colton \& Casper, 1996). In particular, occupations that place particular demands on the voice - such as teaching, singing, and acting--are known risk factors for voice problems (Fritzell, 1996; Jones, Sigmon, Hock, Nelson, Sullian, \& Ogren, 2002; Titze, Lemke, \& Montequin, 1997; Verdolini \& Ramig, 2001). Clinical consequences include phonotraumatic lesions and muscle tension dysphonia as well as perceptual consequences such as dysphonia and vocal fatigue.

Some conditions affecting voice may be treated surgically (e.g. Colton \& Casper, 1996; Sataloff, 1996; Benninger, Jacobson, \& Johnson, 1994; Boone D \& McFarlane, 1994; Aronson, 1990; Rubin, Sataloff, Korovin, \& Gould, 1995). However, most clinicians agree that the predominant treatment approach for phonogenic pathologies lies with behavioral intervention. Such intervention commonly addresses "vocal hygiene" 
The Influence of Clinical Terminology on Self-Efficacy for Voice

(e.g. increased hydration, decreased inflammatory influences and decreased voice use; Chan, 1994; Roy, Gray, Simon, Dove, Corbin-Lewis, Stemple, 2001; Verdolini, 2000) as well as phonatory biomechanics (e.g. Colton \& Casper, 1996; Boone \& McFarlane, 1994; Verdolini, 2000; Gerdeman, Glaze, \& Stemple, 2000). Clearly, patient compliance is central to the success of behavioral treatments (Titze \& Verdolini, in preparation; Verdolini-Marston, Burke, Lessac, Glaze, \& Caldwell, 1995). Stated differently, assuming that behavioral voice-therapy programs are generally well founded, patients' adherence to clinical recommendations would seem critical to treatment outcome.

A complication is that patient compliance is not a given. A broad sector of the medical literature attests to challenges around compliance in healthcare in general. Germane to the present study, one factor that has received substantial attention in the compliance literature has to do with "self-efficacy" — defined as one's belief in one's ability to carry out a specific behavior successfully (Bandura, 1977). A large body of healthcare literature indicates that patient-perceived self-efficacy for specific therapeutic behaviors is a key variable in predicting patient compliance. The present study extends prior investigations in other domains to evaluate the proposal that common practices in voice disorder management — in particular practices associated with common clinical language--may affect patients' self-efficacy for voice. If some indication of meaningful findings is found in the present study, motivation will be provided for future studies to explore the question in larger-scale series and also to investigate other issues around selfefficacy for voice.

The introduction to this paper discusses in turn: (a) Causes of voice disorders, their effects on quality of life, and the relevance of patient compliance in treatment; (b) 
The Influence of Clinical Terminology on Self-Efficacy for Voice

the role of self-efficacy on patient compliance; (c) factors affecting self-efficacy; (d) gaps in the literature; and (e) general experimental hypotheses and specific experimental questions.

$\underline{\text { Voice disorders: causes, effects on quality of life, and relevance of patient }}$ compliance in treatment. Voice disorders can arise from a large number of causes, including mechanical, neuromuscular, chemical, immunologic, psychological, and idiopathic factors affecting voice production (for example, Colton \& Casper, 1996; Verdolini, Rosen, \& Branski, in press; Hedge, 1995; Sataloff, 1991; Benninger et al. 1994; Boone \& McFarlane, 1994; Gerdman et al. 2000). Although exact numbers have not been reported, clinical evidence suggests that mechanical factors associated with voice use are among the most common. Repetitive phonation with large inter-vocal fold impact stress has been strongly implicated as a primary cause of phonotraumatic vocal fold lesions including nodules, polyps, and possibly vocal fold cysts (Jiang \& Titze, 1994). Impact stress, in turn, has been associated with vocal fold hyper-adduction (Berry et al., 2001; Jiang \& Titze, 1994). Phonotraumatic lesions generally produce a series of sequelae including hoarseness, vocal fatigue, and compromise of high-frequency phonation (Verdolini et al., in press;). Interestingly, phonation involving limited adduction due to muscular tension has been implicated in another set of common voiceuse related voice disorders that fall under the rubric of "non-adducted hyperfunction" (Hillman et al., 1997) or "muscle tension dysphonia" (Colton \& Casper, 1996;Roy, Bless, Heisey, \& Ford, 1997; Roy, Ford, \& Bless, 1996; Verdolini et al., in press). In such cases, vocal fold lesions do not develop, but affected individuals experience substantial physical phonatory discomfort and fatigue. 
The Influence of Clinical Terminology on Self-Efficacy for Voice

Phonogenic voice disorders are also often associated with a broader impact on quality of life. Numerous studies have reported such effects. According to a study by Smith and colleagues (Smith et al., 1996), 75\% of patients presenting to large voice clinics in the Midwest reported moderate or worse negative social effects because of voice problems; $65 \%$ reported moderate or worse depression because of voice problems; and $76 \%$ predicted a moderate or worse negative impact on future job performance because of voice. Other studies focusing on teachers - the highest-risk high volume population for a voice disorder (Verdolini \& Ramig, 2001) - indicate that 20-33\% of all teachers miss work because of voice problems (Sapir, Keidar, \& Marthers-Schmidt, 1993). Across all teachers, the average number of workdays lost per year due to voice problems was 0.5-1.0 days (Smith, Kirchner, Taylor, Hoffman, \& Lemke, 1998). Moreover, $39 \%$ of all teachers reduced work because of voice problems (Smith, et al 1998). Of equal concern, evidence suggests that hoarseness in teachers may reduce cognitive functioning in students (Morton \& Watson, 2001). Finally, economic costs of voice problems in teachers, for treatments and substitute personnel alone, have been estimated at a minimum of $\$ 2$ billion annually in the United States alone (Verdolini \& Ramig, 2001).

The foregoing statistics are just a few examples of quality-of-life and economic costs of voice disorders. However, numerous other data have been reported (see for example, Ma \& Yiu, 2001; Mattiske, Oates, Greenwood, 1998; Hogikyan \& Rosen, 2002). The bottom line is that although voice problems may seem to involve "only hoarseness," such problems often produce real quality-of-life, social, and economic costs, 
The Influence of Clinical Terminology on Self-Efficacy for Voice

and are categorized as disabilities according to the World Health Organization's classification (WHO, 1997).

Relevant to the present study, behavioral treatments are the first-line approach for many voice problems, especially those deriving from voice use (Colton \& Casper, 1996; Boone \& McFarlane, 1994; Rubin et al. 1995). Most treatments focus on a combination of vocal hygiene work (hydration and limitation of laryngeal irritants in particular) and work on phonatory biomechanics to address etiologic and maintaining factors (e.g. Verdolini, 1998; Roy et al. 2001; Benninger, Jacobson, Johnson, 1994; Rubin et al. 1995). Various lines of evidence suggest that such work is relevant to improvement of the underlying clinical condition and clinical profile (for reviews, see Ramig \& Verdolini, 1998; Pannbacker, 1998). A corollary is that behavioral treatments require patient participation. In fact, some data within the voice domain suggest that the effectiveness of various approaches to voice therapy depends more on patient compliance than on the specific details of the therapy program (Verdolini-Marston, Burke, Lessac, Glaze, \& Caldwell, 1995). Thus, for clinicians, a central concern regards the identification of factors that may influence compliance. This issue is considered next.

Factors affecting compliance with healthcare directives. Review of the literature suggests that numerous variables affect patients' compliance with medical directives. Examples include patient perception of disease severity (Losato, Joiner, Pettit, Chorot, \& Sandin, 2001), patient-clinician rapport (Ben-Sira, 1976), cultural norms (Verdolini \& Ramig, 2001), family support (Gordis, Markowitz, \& Lillenfeld, 1969), and self-efficacy (McAuley, Talbott, \& Martinez, 1999; Titze \& Verdolini, in preparation). Of central interest for the present study is self-efficacy. Self-efficacy is defined as one's belief in 
The Influence of Clinical Terminology on Self-Efficacy for Voice

one's ability to carry out a specific behavior successfully-relative to healthcare, the focus is a specific therapeutic behavior (Bandura, 1977). The construct of self-efficacy has been the focus of intense research in a wide range of domains, including education, psychology, psychiatry, athletics, business, employment, athletics, and relevant to the present study, healthcare.

The concept of self-efficacy is grounded in social cognitive theory. A key construct in that theory is that people are capable of influencing their cognitive processes and actions by way of self-reflection and evaluation of experiences and thoughts (Bandura, 1986,). More broadly, the view is that human action occurs within a framework that relates environmental, personal (cognitive, affective, and biological) and behavioral factors interactively (Bandura, 1986). In sum, "What people think, believe, and feel affects their behavior" (Bandura, 1986). In fact, numerous studies show that behavior is better predicted by people's beliefs about their capabilities than by past performance (Bandura, 1986). Beliefs are thought to affect functioning by (a) influencing people's choices; (b) influencing people's effort, perseverance, and resilience; and (c) influencing people's beliefs on thought patterns and emotional reactions (Bandura, 1986).

Interestingly, self-efficacy has been shown to be state- (behavior or situation-) rather than trait- (personality) specific (Grembowski et al. 1993). That is, self-efficacy is not the same as self-esteem. It can vary from high to low within a given individual, depending on context (Clark \& Dodge, 1999).

Self-efficacy has been identified as one of the most potent predictors of healthrelated behavior (Clark \& Dodge, 1999; Smith, Rublein, Marcus, Brock, \& Chesney, 
The Influence of Clinical Terminology on Self-Efficacy for Voice

2003; Ludman, Katon, Bush, Rutter, Lin, Simon, VonKorff, \& Walker, 2003). Literally hundreds of studies over the past decades have attested to this conclusion, which is among the most robust ones in the healthcare compliance literature: the likelihood of seeking treatment and completing treatment programs has commonly been reported to increase with increasing self-efficacy (e.g. Grembowski, et al. 1993; Smith et al. 2003). Examples of reports to this effect have included studies on topics as diverse as osteoporosis (Blalock et al., 2002), alcoholism (Monti et al., 2001), depression (Ludman et al. 2003); renal transplantation (Tucker et al., 2002); atopic dermatitis (Ohya et al., 2001); HIV retroviral infection (Smith et al., 2003) ; exercise prescription (Kaplan, Atkins, \& Reinsch 1994), exercise and weight issues in the elderly in particular (Grembowski, et al. 1993); heart disease in elderly females (Clark \& Dodge, 1999); multiple sclerosis rehabilitation (Riazi, Thompson, \& Hobart, 2004), rheumatoid arthritis (Hill, Bird, \& Johnson, 2001), coping with post-traumatic stress (Benight \& Bandura, 2004), and cancer patients' interest in music therapy (Burns, Sledge, Fuller, Daggy, \& Monahan, 2005).

Thus, there is little question in the literature that self-efficacy is a potent factor in predicting clinical compliance. A relevant question for the present study regards which factors may in turn affect self- efficacy. This question is the focus of the next paragraphs.

Factors affecting self-efficacy. The literature identifies four sources of selfefficacy: (a) mastery experience; (b) vicarious experience; (c) social and verbal persuasions; and (d) somatic and emotional states (e.g. Bandura, 1986). Mastery experience is considered among the most important sources (1986). Therefore, successful experiences are seen as critical for the development of self-efficacy. Vicarious 
The Influence of Clinical Terminology on Self-Efficacy for Voice

experiences of others' performance are suggested to occur partly through personal social comparisons. Self-efficacy is affected if the observer considers that she has similar ability to the performer. Verbal persuasions, which are central to the present study, involve verbal judgments or manipulations by others (e.g. Zeldin \& Pajares, 1997). Such persuasions are not to be confused with empty praise, but rather cultivation of belief in one's ability and ensurance that success in a specific area is achievable. According to Bandura (1986), it is easier to weaken self-efficacy with negative persuasions than to strengthen it with positive encouragement. Finally, somatic and emotional states associated with anxiety, stress, arousal, fatigue, and mood have a reciprocal relation with self-efficacy: such states both affect self-efficacy and are affected by it. Aversive thoughts and fears around capabilities decrease self-efficacy (Bandura, 1986).

Examples of specific studies around some of these issues have assessed the role of social support and affect in the development of self-efficacy. For example, social support from an exercise cohort as well as affect during exercise have been shown to influence self-efficacy for exercise - and also long-term physical activity--in an elderly population (McAuley, Jerome, Elavsky, Marquez, \& Ramsey, 2003). In another study, subjects who exercised in a socially enriched as opposed to bland, non-social environment reported more pleasure with the environment and higher levels of satisfaction and achievement with their workouts and also higher self-efficacy ratings (McAuley, Talbot \& Martinez, 1999). However, most directly pertinent to the present investigation are studies looking at feedback around performance, which relate to a combination of mastery experience, verbal persuasion, and affect-related variables. One example is a study that assessed the effect of false feedback around exercise to Non-Latina White and Latina women, 
The Influence of Clinical Terminology on Self-Efficacy for Voice

assigned to either high or low self-efficacy conditions. Women in the high-efficacy group were verbally informed they had superior cardiovascular fitness during an exercise trial, while those in the low-efficacy group were told they were in the bottom $20^{\text {th }}$ percentile for cardiovascular abilities. Individuals in the high-efficacy group reported greater energy and less fatigue post-exercise, whereas the low-efficacy group was more fatigued and less interested in further trials (Jerome, Marquez, McAuley, Canaklisova, Snook, \& Vickers, 2002). Results from this study demonstrate that information we provide people about their basic capabilities within a given task domain can affect selfefficacy for that domain.

Gaps in the literature and issues to address. The foregoing findings attest that considerable data exist in the literature pointing to a critical influence of self-efficacy on behavior across a wide array of domains. Literature also indicates self-efficacy is modulated by a combination of mastery experiences, vicarious experiences, verbal or social persuasion, and affect. Regrettably, data on self-efficacy for voice have not yet been formally reported. Thus, a gap is identified around this variable in voice-related health care.

Moreover, concerns have been raised that highly common clinical practices have specific potential to harm voice-related self-efficacy. Specifically, a concern has been raised that the use of the terms "abuse/misuse" in voice care may harm patients' selfefficacy for voice, and thus reduce patient compliance and ultimately clinical outcome (Verdolini, 1999). The terms "abuse/misuse" are broadly used in both speech-language pathology and otolaryngology (for example, Colton \& Casper, 1996; Hedge, 1995;

Sataloff, 1991; Benninger et al. 1994; Aronson, 1990; Boone \& McFarlane, 1994; Rubin 
The Influence of Clinical Terminology on Self-Efficacy for Voice

et al. 1995). Vocal abuse is generally used to refer to issues of "quantity" in voice production, i.e. voicing too much, too long, and/or too loud (Colton \& Casper, 1996; Boone \& McFarlane, 1994; Aronson, 1990; Sataloff, 1991). Vocal misuse generally refers to vaguely defined deviations in the "quality" of voice production mechanisms (e.g. "muscle misuse," poor "vocal efficiency," non-“optimal pitch;" etc.; Colton \& Casper, 1996; Hedge, 1995; Boone \& McFarlane, 1994). Concerns have been raised around the use of these terminologies at multiple levels (Verdolini, 1999). The central concern for the present study is the terms' potential effect on patients' self-efficacy for voice, and thus clinical outcome. The arguments are as follows. "Abuse" and "misuse" are not "nice words." Most important, they are certainly not compliments. It is not difficult to imagine that informing a patient that she has "abused" or "misused" her voice counts as negative verbal persuasion, harming one's sense of mastery and also affect. However, data are lacking around this claim. The present study addresses this gap by providing preliminary information about the potential effect of the terms' use on voicerelated self-efficacy in adults with self-reported voice problems.

Experimental questions and hypothesis. The primary purpose of the present study is to provide preliminary data on the proposed hypothesis that clinical use of the terms vocal "abuse/misuse" harms self-efficacy for voice. Specific experimental questions are: (1) Can any evidence be found that exposure to "abuse/misuse" language in relation to voice disorders harms self-efficacy for voice in a small subject cohort, that might justify future, larger-scale studies? And (2) If evidence is found suggesting any effect of clinical language on self-efficacy for voice, what number of subjects should be targeted in future 
The Influence of Clinical Terminology on Self-Efficacy for Voice

studies to evaluate the fundamental hypothesis stated, based on power analysis from the present data set?

\section{$\underline{\text { Methods }}$}

\section{$\underline{\text { Participants }}$}

Teachers were targeted as participants in the present study because, as noted, "teacher" has been robustly confirmed in the literature as a high-risk, high-volume occupation for voice disorders (Fritzell, 1996; Jones, Sigmon, Hock, Nelson, Sullian, \& Ogren, 2002; Miller, \& Verdolini, 1995; Titze, Lemke, \& Montequin, 1997; Russell, Oates, \& Greenwood, 1998; National Center for Voice and Speech, 1993; Verdolini \& Ramig, 2001). Thus, targeting teachers in the investigation of self-efficacy for voice has high societal and clinical relevance. Moreover, the participation of a single occupational category in the study would likely limit variability in the data due to underlying voice condition, age, occupation, and overall cognitive and health status.

Teachers were recruited from the Pittsburgh Public School District, using individual fliers that had been pre-approved by the University of Pittsburgh Institutional Review Board and the Pittsburgh Public Board of Education Assessment Office. Approximately 1,750 fliers were distributed via US mail, requesting administrative assistants to place one flier in each teacher's mailbox at his or her school. Fliers invited teachers who had current or past self-identified voice problems to participate in a study about the causes and effects of voice problems in teachers, and also in an information session about voice disorders in teachers. The only exclusion criterion was that subjects could not have had any prior voice therapy. The reason for that exclusion was to limit 
The Influence of Clinical Terminology on Self-Efficacy for Voice

participants' prior exposure to terminology around the origins of phonogenic voice problems.

Twenty-eight teachers responded to the fliers by contacting the primary investigator to indicate an interest in the session. However, only 15 teachers ended up presenting for actual participation in the study (13 women and 2 men). As indicated in Data reduction below, one subject failed to complete experimental procedures according to protocol, and data for that individual were excluded from all analyses. Thus, the final subject set included data from 14 subjects, seven subjects in each of two experimental groups described shortly: an "abuse/misuse" terminology group, and a "phonotrauma/muscle tension" terminology group. Each group had one male and six females. All subjects were compensated $\$ 10$ for their time.

\section{$\underline{\text { Procedures }}$}

All subjects participated in the study at the same time, during an evening session held in the Department of Communication Science and Disorders at the University of Pittsburgh. Arrival time was scheduled for 4:30 p.m. After the subjects' arrival, a computer-generated random number table (www.randomizer.org) was used to identify 9 of the 15 subjects who attended as targets of reliability testing, described shortly. After all of the subjects arrived and were seated in a conference room, they were individually informed that they had been randomly assigned to one of two exposure groups, named group A, and group B, and were given an identifying number that corresponded to the group letter and subject number (e.g. subject A1, subject B6, etc.). The same random number table was used to generate these assignments as was used to identify subjects who would receive reliability testing. The appointment of 6 females and 1 male per 
The Influence of Clinical Terminology on Self-Efficacy for Voice

group was purely random. The 9 subjects selected for reliability testing were then given the Voice Self-Efficacy Questionnaire, described shortly, to complete. The examiner wrote each subject's identification number (e.g. B4) on the questionnaire before it was collected. Then, an announcement was made that subjects should proceed to one of two classrooms, depending on their group assignment. No other information was provided at that time. Two locations were used for the subsequent experimental sessions to avoid contamination of information across groups during the experimental phase of the study. Once subjects were seated in their assigned rooms, they were given the Voice SelfEfficacy Questionnaire to complete as a pre-test. Subjects who had already completed the questionnaire filled it out a second time, and data from the second form were used as the pre-test in that case. Following questionnaire completion, subjects viewed one of two experimental videotapes, without any commentary from the investigators: an "abuse/misuse" tape, and a "phonotrauma" tape, also described below. After viewing the tapes (about $15 \mathrm{~min}$ ), subjects completed the Voice Self-Efficacy Questionnaire one last time. After questionnaires were collected, subjects returned to the original conference room where they were debriefed regarding the experiment and its hypotheses. Subjects then received a 45-min informational session on common causes and treatments of voice problems in teachers, by a licensed speech-language pathologist who specialized in professional voice. That information session was not part of the experimental procedures, and no data were gathered around it.

$\underline{\text { Materials }}$

$\underline{\text { Video presentation materials. }}$. The primary experimental materials involved two educational videotapes on voice problems in teachers, which were expressly created for 
The Influence of Clinical Terminology on Self-Efficacy for Voice

the study. Tapes were made by a licensed, certified, doctoral-level speech-language pathologist specialized in voice, who was unaware of the experimental hypotheses and declared that she had no bias for or against the study's key terms: "abuse/misuse" or "phonotraumatic behaviors/muscular tension." Clinical interaction with this speechlanguage pathologist by the investigators over an extended period of several months or more prior to the experiment confirmed this impression, as the clinician was observed to regularly utilize both sets of terms in the clinical setting.

The tapes reviewed common conditions affecting voice in teachers, their causes, and their treatments. Both tapes were created from a single template that was modified only in key phrases for its two versions. Specifically, both texts provided information about the following issues, in identical order: (a) frequency of voice disorders in the general population and in teachers, and costs of voice problems in teachers; (b) symptoms of common voice problems; (c) believed causes of common voice problems in teachers; (d) basic phonatory physiology in relation to injury; (e) issues of self-care in voice; (f) physical consequences of etiologic behaviors, i.e. common phonotraumatic laryngeal pathologies (nodules, polyps, cysts, and edema); (g) recommendation to seek professional evaluation and treatment for voice problems (names and contact information for specialized local laryngologists were provided); (h) reiteration of self-care instructions awaiting professional handling.

The tapes' texts first diverged in section (c) above, on causes of common voice problems in teachers. Text in the "abuse/misuse" intervention identified "vocal abuse/misuse" as the primary cause of phonogenic voice problems. Text in the 
The Influence of Clinical Terminology on Self-Efficacy for Voice

"phonotrauma" intervention identified "phonotraumatic behaviors" and "muscular tension" as the primary cause of these problems.

The next part of the tapes in which texts diverged was section (e) above, which introduced issues of self-care in voice. Individuals in the "abuse/misuse" group were told they should cease vocal abuse/misuse. Individuals in the "phonotrauma" group were told to address phonotraumatic behavior and muscular tension by seeking appropriate assistance. The final part of the tapes in which texts diverged involved section (h), which reiterated self-care instructions noted in section (e). With these exceptions, the tapes used identical texts and images. All subjects were provided a written copy of the texts in PowerPoint format to follow during the video presentations (Appendix A and Appendix B).

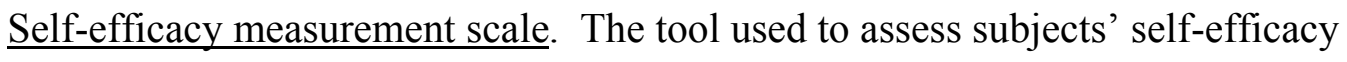
for voice before and after interventions was the Voice Self-Efficacy Questionnaire (VSEQ), which was created expressly for this study. The development of the questionnaire was guided by numerous self-efficacy questionnaires generated and validated for use in other health-related domains, such as stuttering (Orstein \& Manning, 1985), chronic obstructive pulmonary disease (Kara \& Asti, 2004) memory deficits (Zelinski \& Gilewski, 2004), childhood depression (Annesi, 2004), diabetes (Rapley, Passmore, \& Phillips, 2003), nursing home care (Yasuko F. 2002), breastfeeding (Dennis, \& Faux, 1999) and chronic pain management (Arnstein, Wells-Federman, \& Caudill, 2001). Also other voice disorder questionnaires, in particular the Voice Handicap Index (Jacobson et al., 1997), were used to guide the development of the VQES. 
The Influence of Clinical Terminology on Self-Efficacy for Voice

The approach to the development of self-efficacy questionnaires in these domains has generally involved researchers in a specific field developing questions related to that field. In most domains, questions targeted self-efficacy for a given behavior across a range of situations. Questions were then typically subjected to statistical testing to identify reliable versus unreliable items, and unreliable ones were removed in the final versions. Moreover, a set of measures was sought that reflected good internal consistency. In the present study, the target was self-efficacy for voice in individuals who had self-declared voice problems but had not yet received any treatment for them. Thus, their ability to judge their voice-related self-efficacy for target behaviors across a range of situations would be limited. For that reason, the questions generated inquired about situation-neutral self-efficacy for voice. Questions were generated by the first author, modulated by the second author (both speech-language pathologists, the second author with approximately $25 \mathrm{yr}$ in voice care) and further evaluated by the project's statistician. The four questions generated using this procedure were the following: (1) How confident are you in your ability to use your voice effectively? (2) How confident are you in your ability to use your voice in a healthy way? (3) How confident are you in your ability to use your voice without harming it? and (4) How confident are you in your ability to use your voice without harming it? (Table 1). The questionnaire instructed subjects to indicate their responses to each of the questions by placing a slash mark on a $100 \mathrm{~mm}$ line that appears below each question. The extreme left on each line reflected not at all confident and the extreme right reflected extremely confident.

[Insert Table 1 here] 
The Influence of Clinical Terminology on Self-Efficacy for Voice

Information regarding data extraction, reliability, and internal consistency is provided under Data reduction and Statistical analyses. The final set of questions that would be included in data analysis would be those that demonstrated intra-rater and intrasubject stability according to criteria indicated shortly.

Relative to validity, the issue of interest was face validity. Self-efficacy is defined as subjects' self-perceived and reported confidence in their abilities around specific behaviors (Clark \& Dodge, 1999). Thus, subjects' responses to self-efficacy questions were taken at face value.

$\underline{\text { Data reduction }}$

Completed Voice Self-Efficacy Questionnaires were assembled in random order and opaque tape was used to obscure subject identification and group assignment information on each form. For each question on each questionnaire, using a standard metric ruler, the first author measured the distance, in $\mathrm{mm}$, from the left-hand side of the line, to the marking that the subject had made. The measured distance was recorded in a computerized table. After all of the questionnaires had been measured, questionnaires were reassembled in a different order, and the first author measured responses again in the same manner as before, with the identification number and group assignment letter covered, to provide data regarding intra-rater reliability as discussed shortly. One score sheet from a subject in the "phonotrauma" group was found to exhibit markings beyond the $100 \mathrm{~mm}$ scale. Data from that subject were therefore excluded from further analysis, making the number of subjects in the two groups equal in the final data set (seven subjects in each group). 
The Influence of Clinical Terminology on Self-Efficacy for Voice

\section{$\underline{\text { Statistical analyses }}$}

$\underline{\text { Reliability and internal consistency. Intra-rater and intra-subject reliability were }}$ calculated using the Pearson correlation coefficient (Pearson $r$ ) and the Interclass correlation coefficient (ICC). Separate values for each statistic were calculated for each of the four questions. Internal consistency was calculated using the Pearson $r$ for all possible pairs of questions for pre-test responses. Control of $\alpha$ inflation was not considered for these statistics; a criterion level of $\alpha=.05$ was set for each of these tests.

Experimental questions. The first experimental question was: Can any evidence be found that exposure to "abuse/misuse" language in relation to voice disorders harms self-efficacy for voice in a small subject cohort, that might justify future, larger-scale studies?

In this preliminary, small-N study, that question was addressed using binomial statistics. Specifically, for each group, the number of responses showing shifts in selfefficacy scores pre- to post-exposure (+/-) would be identified relative to the total number of responses (e.g. number of positive shifts, number of negative shifts, and number of zero shifts, each relative to a total of 28 responses for that group: 4 questions times 7 subjects). The response valence showing the greatest proportion within each group would be submitted to a binomial test to assess the likelihood that the result occurred by chance. Evidence consistent with the hypothesis that self-efficacy for voice may be harmed by exposure to "abuse/misuse" language would be seen by either (a) a significant likelihood of reduction in self-efficacy scores in the "abuse/misuse" group pre- to postexposure, or (b) a significant likelihood of increase in self-efficacy scores in the "phonotrauma/muscle tension" group, but not in the "abuse/misuse" group. Given the 
The Influence of Clinical Terminology on Self-Efficacy for Voice

preliminary nature of the inquiry, the overall $\alpha$ level for both binomial tests

("abuse/misuse" and "phonotrauma" groups) was set to .10. Thus, the criterion level for each test was $\alpha=.05$.

The second experimental question was: (2) If evidence is found suggesting any effect of clinical language on self-efficacy for voice, what number of subjects should be targeted in future studies to evaluate the fundamental hypothesis stated, based on power analysis from the present data set? That question would be addressed conducting power analysis with a criterion of .80 power and an alpha level of .05 .

$\underline{\text { Results }}$

\section{Properties of the Voice Self-Efficacy Questionnaire}

Pre-Test Group Similarity. A T-test was completed to compare pre-test scores of the two experimental groups for group similarity (Table 2). The groups were found to have no significant differences between them at the pre-test level, thus showing that amount of change on the post-test Voice Self-Efficacy Questionnaire were not influenced by individual subject differences on the pre-test. The distribution of pre-test scores per group, per question is conveyed on a scatter plot (Figure 1).

Reliability. One subject's response on the first question extended the $100 \mathrm{~mm}$ line, and was discarded for question \#1, therefore question \#1 was analyzed with 8 subjects, and questions 2-4 were analyzed with 9 subjects. Intra-rater reliability correlations were $r \geq .99$ for all questions (Table 3). A Paired Samples T-Test analysis 
The Influence of Clinical Terminology on Self-Efficacy for Voice

conducted also determined no significant differences between the measurement of the Voice Self-Efficacy Questionnaire from time one to time two (Table 4). Intra-subject correlations, assessing test-retest reliability, were $r=.78-.95$ for all questions (Tables 5 and 6). Test-retest reliability results for question $\# 2$ were skewed by one participant whose response varied by $24 \mathrm{~mm}$ pre- to post-test, exceeding all other participant's reliability performance, resulting in the $r=.78$ for Question \#2.

[Insert Tables 3, 4, 5, and 6 here]

Internal consistency. Results for internal consistency showed that correlations between responses for all pairs of questions ranged between $r=-.498$ and .884 (Table 7). Typical standards set the reliability coefficient to .70 for researcher-developed instruments (Nitko, 2001, p. 76.) Thus, the majority of items did not meet the criterion. However, the number of items on a test affects these values: greater reliability is seen with increased numbers of items. Thus, internal consistency was difficult to evaluate in the present data set, due to the inclusion of only four questions. Inspection of Table 4 shows that the negative correlation between responses to Question \#1 and \#4 $(r=-.498$, $p=.07)$ was mainly responsible for the apparent low internal consistency.

[Insert Table 7 here]

\section{Effect of clinical language on self-efficacy for voice}

Individual VSEQ data as well as group means for each question and for the questionnaire as a whole are shown in Table 8. Numerically, on average, subjects in both "abuse/misuse" and "phonotraumatic behaviors/muscular tension" groups improved in self-efficacy scores pre- to post-exposure to instructional videos. The exception was Question \#1 (“How confident are you in your ability to use your voice effectively?"). As 
The Influence of Clinical Terminology on Self-Efficacy for Voice

shown in Table 8, average scores for both groups decreased pre- to post-exposure for that question.

[Insert Table 8 here]

Interestingly, although self-efficacy scores generally improved pre- to postexposure in both groups (with the exception of Question \#1), average scores improved about twice as much in the "phonotrauma" group as compared to the "abuse/misuse" group for Questions \#2-4. Further, scores decreased about half as much for Question \#1 in the "phonotrauma" group (Table 8). However, as anticipated in this small-N preliminary study, statistical power was generally poor to detect differences in group averages using parametric tests (power $=.42$ for Question \#1;.06 for Question \#2;.14 for Question \#3, and .67 for Question \#4, using Analysis of Covariance, with exposure group ("abuse/misuse" or "phonotrauma/muscle tension") as the independent variable, pretest response to one of the four VSEQ questions as the covariate, and post-test response to the same question as the dependent variable.

Results from the binomial evaluation of the data were more illuminating. Inspection of Table 8 reveals that across all subjects and questions, in the “abuse/misuse” group, 13/28 responses were poorer pre- to post-test, 11/28 responses were improved pre- to post-test, and 4/28 responses were unchanged. In contrast, in the “phonotrauma/muscle tension” group, 20/28 responses improved pre- to post-test, 7/28 responses were poorer pre- to post-test, and 1 response was unchanged. Binomial statistical analysis revealed that the decreased self-efficacy scores in the "abuse/misuse" group (11/28 responses) and in the "phonotrauma/muscle tension" group (7/28 responses), as well as the responses that showed no change (4/28 responses in the 
The Influence of Clinical Terminology on Self-Efficacy for Voice

"abuse/misuse group and 1/28 responses in the "phonotrauma/muscle tension" group) were not statistically different from chance. Increased self-efficacy scores for the "abuse/misuse" group were also not found to be significant, or different from chance. Only the increase in self-efficacy scores for the "phonotrauma/muscle tension" group (20/28 responses) were found to be significant and exceeded chance $(p<.05)$.

A Chi-Square test was conducted, and as with the binomial test, found a statistical difference between the 11 increased/28 possible self-efficacy responses of the "abuse/misuse" group, and the 20/28 increased self-efficacy responses of the "phonotrauma" group to the $<.05$ level, with the Chi-Square $=5.85, \mathrm{p}=.016$, and the effect size as correlation was .323 .

Conversely, a secondary analysis of the pre-post response data was conducted. The responses pre-test to post-test were re-coded and converted into a categorical variable. Increases in self-efficacy pre to post, regardless of amount of increase, were coded as +1 . Decreases in self-efficacy pre to post, regardless of amount of decrease, were coded as -1 . Responses that showed no change pre to post were coded as 0 . After the responses were coded, they were averaged and a T-test was used to compare the average amount of change, per to post, per group. Effect sizes were also calculated. For each question, respectively, $d=.65, .54, .43$, and .23 . Differences with this method of recoding and T-test analysis, as with the ANCOVA, were not found to be significant. The results of the T-test and corresponding effect sizes are included in Table 9.

[Insert Table 9 here] 
The Influence of Clinical Terminology on Self-Efficacy for Voice

\section{$\underline{\text { Power analysis }}$}

Using the effect sizes obtained from the binomial data set, the number of subjects was calculated that would be needed to achieve .80 power at the .05 criterion level, for a one-sided parametric test. The calculation indicated that 20 subjects per group (i.e. a total of 40 subjects) would be needed to achieve .80 power, using a similar experimental paradigm and similar effect sizes.

\section{$\underline{\text { Discussion }}$}

The first experimental question in the present study was: Can any evidence be found that exposure to "abuse/misuse" language in relation to voice disorders harms selfefficacy for voice in a small subject cohort, that might justify future, larger-scale studies? Results indicated that some evidence to this effect was found, using two non-parametric evaluations of the data. Although self-efficacy scores were not reliably decreased pre- to post-exposure to "abuse/misuse" terminology, the likelihood of a reliable increase in selfefficacy found in the "phonotrauma/muscle tension" group appeared compromised by “abuse/misuse" language.

At that level, evidence was found that can motivate future, larger-scale studies about the effect of clinical language on self-efficacy for voice. Effect size analysis of the binomial data indicates that at least 20 subjects would be needed per exposure group to achieve $80 \%$ power to detect group differences in self-efficacy modulations using a similar experimental design. However, the self-efficacy instrument should be further developed to achieve improved internal consistency. Self-Efficacy scores of both the "abuse/misuse" and "phonotrauma/muscle tension" group decreased in response to question \#1 (“How confident are you in your ability to use your voice effectively?") 
The Influence of Clinical Terminology on Self-Efficacy for Voice

which may, as previously stated, have been due to differences surrounding the definition of "effectively" and perhaps should be re-worded. Questions \#2 and \#3 ("How confident are you in your ability to use your voice in a healthy way?" and "How confident are you in your ability to use your voice without harming it?") should definitely be retained because of their relatively tight co-variation. Question \#4 ("How confident are you in your ability to change the way you use your voice?") appears to be negatively correlated with the other questions, and may require omission or re-wording on a final version.

Having said as much, the question of potential bias in the results should be addressed. Our author group has an established, published bias around the potential negative effects of the terms "abuse/misuse" (Verdolini, 1999). The legitimate question arises around the possibility that such bias influenced the results from this preliminary study. That possibility should be investigated in future studies by other author groups. In the interim, two factors might be argued to limit that concern in the present data set. First, exposures to "abuse/misuse" and "phonotrauma/muscle tension" were delivered via videotape to an investigator who not only was unaware of the experimental hypotheses. That investigator also declared to have no bias around either set of terms, and uses both sets regularly in clinical practice. Another issue is that perhaps the wording in the exposures biased the results. In particular, the "abuse/misuse" text instructed patients to stop vocal abuse. The "phonotrauma/muscle tension" text told patients they could address their voice issues by seeking competent professional care. Admittedly, possibly this difference in emphasis influenced the results. Mitigating against this argument is the observation that in fact, people with voice problems should be capable of "stopping abuse/misuse" on their own, whereas people who are told to seek help for their problems 
The Influence of Clinical Terminology on Self-Efficacy for Voice

might infer they cannot address them on their own. Seen in that light, arguably, exposure to the text in the "abuse/misuse" should increase self-efficacy more than exposure to the text "phonotrauma/muscle tension," which did not occur. In any event, the question about potential bias is an interesting an important one and should be explored in future studies.

Beyond this concern, which is an important one, two aspects of these findings are interesting for discussion. First is the failure to see clear increases in self-efficacy for the “abuse/misuse" group, subsequent to exposure to educational material around voice disorders. This finding is inconsistent with reports indicating patient information and education are factors that may increase self-efficacy (e.g. Smith et al., 2003). Specifically, self-efficacy for disease management has been shown to increase more in experimental groups who receive education about their illness and training on managing their illness, as compared to control groups who receive only the management training (Ludman et al, 2003). In the present study, exposure to "abuse/misuse" terminology appeared to mask anticipated increases in self-efficacy, and thus indeed to harm it. The issues are non-trivial and should be investigated in future studies.

Future studies should also be conducted to assess the mechanisms by which clinical language may affect self-efficacy for voice. In particular, mastery experience, vicarious experience, verbal persuasion, and affect should be investigated as potential mediators (Bandura, 1986;). Finally, the effect of voice-related self-efficacy on patient compliance and clinical outcome should be investigated as a critical concern in the management of voice disorders. 
The Influence of Clinical Terminology on Self-Efficacy for Voice

\section{Bibliography}

American Speech-Language Hearing Association Special Interest Division 3: Voice and Voice Disorders. Classification Manual for Voice Disorders-I. Unpublished.

Annesi, J.J. (2004). Relationship between self-efficacy and changes in rated tension and depression for 9- to 12-yr.-old children enrolled in a 12-wk. after-school physical activity program. Perceptual Motor Skills. 99(1): 191-4.

Arnstein, P., Wells-Federman, C., Caudill, M. (2001). The Effect of an Integrated Cognitive-Behavioral Pain Management Program on Pain Intensity, Self-efficacy Beliefs and Depression in Chronic Pain Patients on Completion and One Year Later. Pain Med. 2(3):238-239.

Aronson, A. (1990). Clinical Voice Disorders: An Interdisciplinary Approach. $3^{\text {rd }}$ edition. New York, NY: Thieme, Inc.

Bandura, A. (1977). Self-efficacy: Towards a Unifying Theory of Behavioral Change. Psychol Rev; 84(2) 191-215.

Bandura, A. (1986). Social foundations of thought and action: A social cognitive theory. Englewood Cliffs, NJ: Prentice Hall.

Benight, C., Bandura, A. (2004). Social Cognitive Theory of posttraumatic recovery: the role of self-efficacy. Behavior Research \& Therapy. 42:1129-1148. 
The Influence of Clinical Terminology on Self-Efficacy for Voice

Ben-Sira, Z. (1976). The function of the professional's affective behavior in client satisfaction. Journal of Health Soc Behav, 17(1): 3-11

Benninger, M., Jacobson, B., Johnson, A. (1994). Vocal Arts Medicine: The care and prevention of professional voice disorders. New York, NY: Thieme Medical Publishers, Inc.

Berry, D.A., Verdolini, K., Montequin, D.W., Hess, M.M., Chan, R.W., Titze, I.R. (2001). A quantitative output-cost ratio in voice production. Journal of Speech Language and Hearing Research. 44(1):29-37.

Blalock, S. J., DeVellis, B. M., Patterson, C. C., Campbell, M. K., Orenstein, D. R., \& Dooley, M. A. (2002). Effects of an osteoporosis prevention program

Boone, D., McFarlane, S. (1994). The Voice and Voice Therapy. $5^{\text {th }}$ edition. Englewood Cliffs, NJ: Prentice-Hall, Inc.

Burns, D.S., Sledge, R.B., Fuller, L.A., Daggy, J.K., \& Monahan, P.O. (2005). Cancer patients' interest and preferences for music therapy. Journal of Music Therapy, $42(3), 185-199$.

Chan, R.W. (1994). Does the voice improve with vocal hygiene education? Journal of Voice. 8(3): 279-91.

Clark, N.M, Dodge, J.A. (1999). Exploring Self-Efficacy as a Predictor of Disease Management. Health Education and Behavior. 72-88.

Colton, R.H., Casper, J.K. (1990). Understanding Voice Problems, A Physiological Perspective for Diagnosis and Treatment. Baltimore: William \& Wilkins.

Dennis, C., Faux, S. (1999). Development and psychometric testing of the Breastfeeding Self-Efficacy Scale. Research in Nursing \& Health. 22(5):399-409

Fritzell, B. (1996). Voice disorders and occupations. Logopedics Phoniatrics Vocology, 
The Influence of Clinical Terminology on Self-Efficacy for Voice

$21,7-12$.

Gerdeman, B.K., Glaze, L.E., \& Stemple, J.C. (2000). Clinical voice pathology: Theory and management (3rd ed.) San Diego: Singular Publishing Group.

Gordis, L., Markowitz, M., Lilienfeld, A.M. (1969). Why patients don’t follow medical advice. J Pediatr. 75(6):957-968.

Grembowski, D., Patrick, D., Deihr, P., Durham, M., Beresford, S., Kay, E., Hecht, J. (1993). Self- Efficacy and Health Behavior Among Older Adults. Journal of Health and

Social Behavior. 34:89-104

Hill, J., Bird, H., Johnson, S. (2001). Effect of patient education on adherence to drug treatment for rheumatoid arthritis: a randomised controlled trial. Ann Rheum Dis. 2001. 60(9):869-75.

Hillman, R.E., Holmberg, E.B., Perkell, J.S., Walsh, M., \& Vaughn, C. (1989). Objective assessment of vocal hyperfunction: an experimental framework and initial results. J Speech Hear Res. 32(2):373-92.

Hedge, N.M. (1995). Introduction to Communication Disorders. Austin, Tx: PRO-ED. Hogikyan, N.D, \& Rosen, C.A. (2002). A Review of Outcome Measurements for Voice Disorders. Otolaryngology Head and Neck Surgery. 126:562-72.

Jacobson, B., Johnson, A., Grywalski, C., Silbergleit, A., Jacobson, G., Benninger, M., Newman, C. (1997). The Voice Handicap Index (VHI): Development and Validation. American Journal of Speech-Language Pathology. 5:66-70. 
The Influence of Clinical Terminology on Self-Efficacy for Voice

Jerome, G.J., Marquez, D.X., McAuley, E., Canaklisova, S., Snook, E., \& Vickers, M. (2002). Self-efficacy effects on feeling states in women. Int J Behav Med. $9(2): 139-54$

Jiang, J., \& Titze, I. (1994). Measurement of vocal fold intraglottal pressure and impact stress. Journal of Voice. 8(2): 132-44.

Jiang, J.J., Verdolini, K., Ng, J., \& Hanson, D.G. (2000). Effects of dehydration on phonation. Annals of Otology, Rhinology and Laryngology, 109, 568-575.

Jones, K., Sigmon, J., Hock, L., Nelson, E., Sullian, M., \& Ogren, F. (2002). Prevalence and Risk Factors for Voice Problems Among Telemarketers. Archives of Otolaryngology - Head and Neck Surgery, 128, 571-577.

Kaplan, R.M, Atkins, C.J., Reinsch, S. (1994). Specific efficacy expectations mediate exercise compliance in patients with COPD. Health Psychology. 3:223-242.

Kara, M., \& Asti, T. (2004). Effect of education on self-efficacy of Turkish patients with chronic obstructive pulmonary disease. Patient Education and Counseling. 55(1): 114-20.

Kreiman, J., Gerratt, V.R. (1998). Validity of Rating Scale Measures of Voice Quality. Journal of the Acoustical Society of America, 104 (3 Pt 1), 1298-1608.

Losato, L., Joiner, T., Pettit, J., Chorot, P., Sandin, B. (2001). health beliefs and illness Attitudes as predictors of breast cancer screening attendance. Eur J Public Health. 11(3): 274-279.

Ludman, E., Katon, W., Bush, T., Rutter, C., Lin, E., Simon, G., Von Korff, M., Walker E. (2003).Behavioural factors associated with symptom outcomes in a primary care-based depression prevention intervention trial. Psychological Medicine. 33: 
The Influence of Clinical Terminology on Self-Efficacy for Voice

1061-1070.

Mattiske, J.A., Oates, J.M., Greenwood, K.M. (1998). Vocal Problems among teachers: a review of prevalence, causes, prevention, and treatment. Journal of Voice. 12(4): 489-499.

Ma, E., \& Yiu, E. (2001). Voice Activity and Participation Profile: Assessing the Impact of Voice Disorders on Daily Activities. Journal of Speech, Language, and Hearing Research. 2001; 44:511-524.

McAuley, E., Talbot, H.M., \& Martinez S. (1999). Manipulating self-efficacy in the exercise environment in women: influences on affective responses. Health Psychology. 18(3):288-94.

Miller, M. \& Verdolini, K. (1995). Frequency of voice problems reported by teachers of singing and control subjects and risk factors. Journal of Voice, 8, 348-362.

Monti, P. M., Rohsenow, D. J., Swift, R. M., Gulliver, S. B., Colby, S. M., Mueller, T. I., et al. (2001). Naltrexone and cue exposure with coping and communication skills training for alcoholics: treatment process and 1-year outcomes. Alcohol Clin Exp Res, 25(11), 1634-1647.

Morton, V., \& Watson, D.R. (2001). The impact of impaired vocal quality on children's ability to process spoken language. Logopedics, Phoniatrics, Vocology, 26: 1725.

Murry, T., \& Rosen, C. (2000). Outcome Measurements and Quality of Life in Voice Disorders. Otolaryngologic Clinics of North America. 33:905-917.

Nitko, A.J. (2001). Educational assessment of students. Upper Saddle River, N.J.: 
The Influence of Clinical Terminology on Self-Efficacy for Voice

\section{Prentice-Hall}

Ohya, Y, Williams, H., Steptoe A, Saito H, Iikura Y, Anderson R, Akasawa A. (2001). Psychosocial factors and adherence to treatment advice in childhood atopic dermatitis. Journal of Investigative Dermatology. 117(4):852-7.

Opacic, D.A. (2003). The relationship between Self-Efficacy and Student Physician Assistant Clinical Performance. Journal of Allied Health. 32:158-166.

Ornstein, A.F., \& Manning, W.H. (1985). Self-efficacy scaling by adult stutterers. Journal of Communication Disorders. 18(4):313-20

Pannbacker, M. (1998). Voice Treatment Techniques: A Review and Recommendations for Outcome Studies. American Journal of Speech Language Pathology. 7(3): 49-64.

Pannbacker, M. (1999). Treatment of vocal nodules: options and outcomes. American Journal of Speech Language Pathology. 8(3): 209-217.

Rapley, P., Passmore, A., \& Phillips, M. (2003). Review of the psychometric properties of the Diabetes Self-Efficacy Scale: Australian longitudinal study. Nursing \& Health Sciences. 5(4):289-297.

Ramig, L.O., \& Verdolini, K. (1998). Treatment efficacy: voice disorders. Journal of Speech Language and Hearing Research. 41(1):S101-16.

Riazi, A., Thompson, A.J., \& Hobart, J.C. (2004). Self-efficacy predicts self-reported health status in multiple sclerosis. Multiple Sclerosis. 10(1):61-6.

Roy, N., Bless, D.B., Heisey, D., \& Ford, C.N. (1997). Manual circumlaryngeal therapy for functional dysphonia: an evaluation of short- and long-term treatment outcomes. Journal of Voice. 11(3):321-31 
The Influence of Clinical Terminology on Self-Efficacy for Voice

Roy, N., Ford, C., \& Bless, D.M. (1996). Muscle tension dysphonia and spasmodic dysphonia: the role of manual laryngeal tension reduction in diagnosis and management. Ann Otol Rhinol Laryngol.105(11):851-6

Roy, N., Merrill, R.M., Thibeault, S., Gray, S.D., \& Smith, E.M. (2004). Voice disorders in teachers and the general population: effects on work performance, attendance, and choice of future careers. Journal of Speech Language and Hearing Research. 47(3): 542-51.

Roy, N., Gray, S.D., Simon, M., Dove, H., Corbin-Lewis, K., Stemple, J.C. (2001). An Evaluation of the effects of two treatment approaches for teachers with voice disorders: a prospective randomized clinical trial. Journal of Speech Language and Hearing Research. 44(2):286-96.

Roy, N., Wienrich, B., Tanner, K., Gray, S.D., \& Stemple, J.C. (2003). Three treatments for Teachers with Voice Disorders: A Randomized Clinical Trial. Journal of Speech Language and Hearing Research. 46(3): 670-688.

Rubin, J., Sataloff, R., Korovin, G., \& Gould, W. (1995). Diagnosis and Treatment of Voice Disorders. Tokyo: IGAKU-SHOIN Inc.

Russell, A., Oates, J., \& Greenwood, K. M. (1998). Prevalence of voice problems in teachers. Journal of Voice, 12, 467-479.

Sapir, S., Keidar, A., \& Mathers-Schmidt, B. (1993). Vocal attrition in teachers: survey findings. European Journal of Disordered Commuication. 28(2):177-85.

Sataloff, R. (1991). Professional Voice: the science and art of clinical care. New York, NY: Raven Press Ltd. 
The Influence of Clinical Terminology on Self-Efficacy for Voice

Smith, E., Verdolini, K., \& Gray, S. (1996). Effect of Voice Disorders on Quality of Life. Journal of Medical Speech Language Pathology. 4:223-244.

Smith, S.R., Rublein, J.C., Marcus, C., Brock, T.P., \& Chesney, M.A. (2003). A medication self-management program to improve adherence to HIV therapy regimens. Patient Education and Counseling. 2003; 50:187-199.

Titze, I.R., Lemke, J., \& Montequin, D. ( 1997). Populations in the U.S. workforce who rely on voice as a primary tool of trade. A preliminary report. Journal of Voice, $11,254-259$.

Tucker, C. M., Fennell, R. S., Pedersen, T., Higley, B. P., Wallack, C. E., \& Peterson, S. (2002). Associations with medication adherence among ethnically different pediatric patients with renal transplants. Pediatr Nephrol, 17(4), 251-256.

Verdolini-Marston, K., Burke, M.K., Lessac, A., Glaze, L., \& Caldwell, E. (1995). Preliminary study of two methods of treatment for laryngeal nodules. Journal of Voice. 9(1):74-85.

Verdolini, K., DeVore K., McCoy, S., \& Ostrem, J. (1998). National Center for Voice and Speech: Guide to Vocology. Iowa City, IA: National Center for Voice and Speech.

Verdolini, K. (1999). Critical Analysis of Common Terminology in Voice Therapy: A Position Paper. Phonoscope. 2:1-8.

Verdolini, K., \& Ramig, L.O. (2001). Review: Occupational risks for Voice Problems. Logopedics, Phoniatrics, Vocology. 26: 37-46.

World Health Organization. International Classification of Impairments, Disabilities and Handicaps. Geneva, Switzerland: 1987. 
The Influence of Clinical Terminology on Self-Efficacy for Voice

Yasuko, F. (2002). Development, reliability and validity of an ADL gap self-efficacy Scale for elderly persons requiring home based nursing care. Journal of Japan Academy of Nursing Science. 22(1):23-32.r

Zeldin, A. L. \& Pajares, F. (1997). Against the odds: Self-efficacy beliefs of women with math-related careers. Paper presented at the meeting of the American Educational Research Association, Chicago.

Zelinski, E.M., \& Gilewski, M.J. (2004). A 10-item Rasch modeled memory selfefficacy scale. Aging and Mental Health. 8(4):293-306. 
The Influence of Clinical Terminology on Self-Efficacy for Voice

Table 1. Voice Self-Efficacy Questionnaire.

Not at all confident

Extremely confident

1. How confident are you in your ability to use your voice effectively?

2. How confident are you in your ability to use your voice in a healthy way?

3. How confident are you in your ability to use your voice without harming it?

4. How confident are you in your ability to change the way you use your voice? 
The Influence of Clinical Terminology on Self-Efficacy for Voice

Table 2

Results of t-tests comparing groups on pretest items

Std.

\begin{tabular}{llrrrr} 
item & group & Mean & Dev. & $\mathrm{t}$ & \multicolumn{2}{c}{$\mathrm{p}$} \\
pre1 & abuse & 64.57 & 20.20 & 1.36 & 0.200 \\
& phonotrauma & 45.71 & 30.77 & & \\
pre2 & abuse & 33.71 & 22.46 & 0.47 & 0.644 \\
& phonotrauma & 28.57 & 17.81 & & \\
pre3 & abuse & 30.57 & 20.11 & 0.26 & 0.803 \\
& phonotrauma & 27.57 & 23.71 & & \\
pre4 & abuse & 41.43 & 30.46 & -1.13 & 0.279 \\
& phonotrauma & 61.14 & 34.48 & &
\end{tabular}


The Influence of Clinical Terminology on Self-Efficacy for Voice
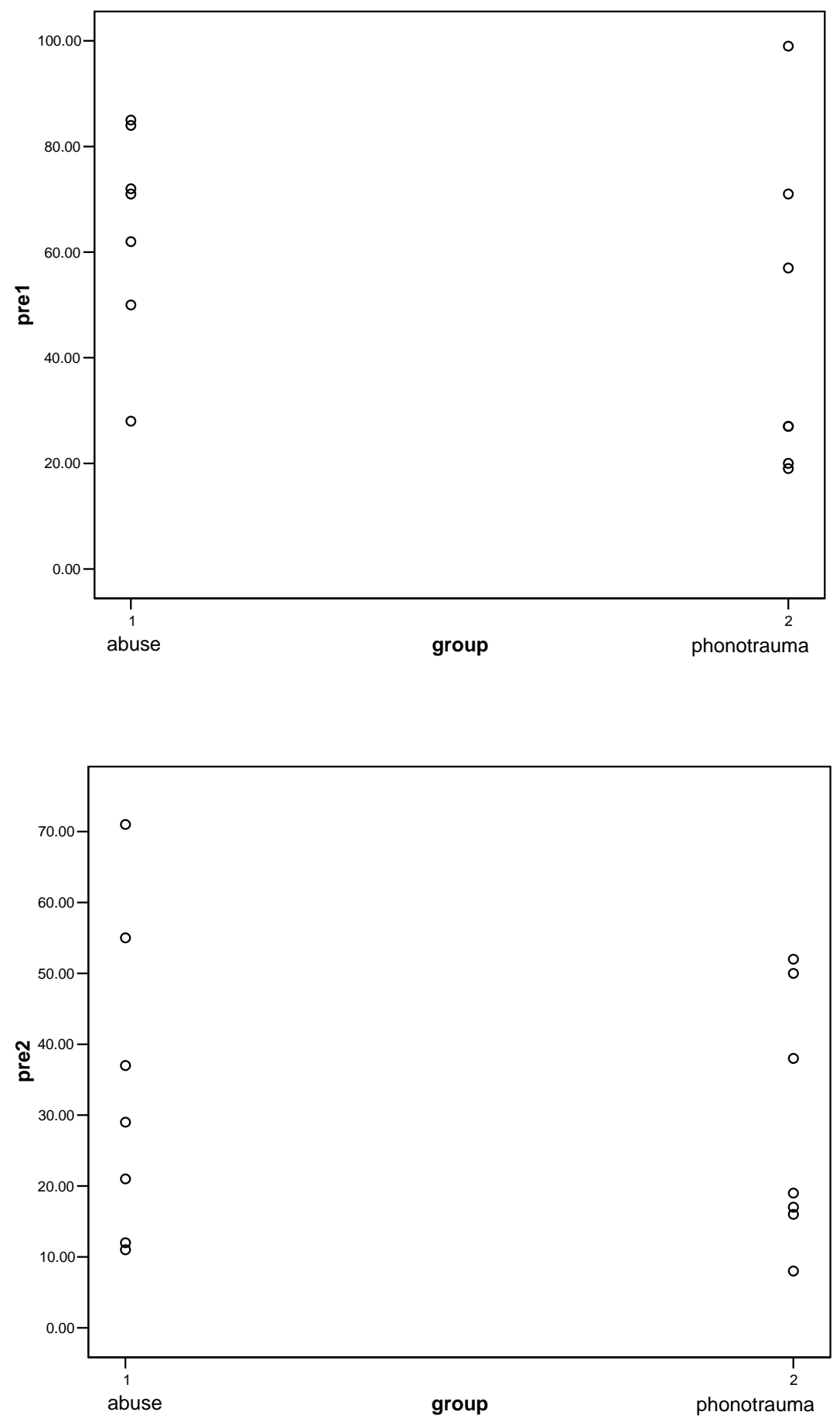

Figure 1. Scatterplot distribution of pre-test similarity 
The Influence of Clinical Terminology on Self-Efficacy for Voice
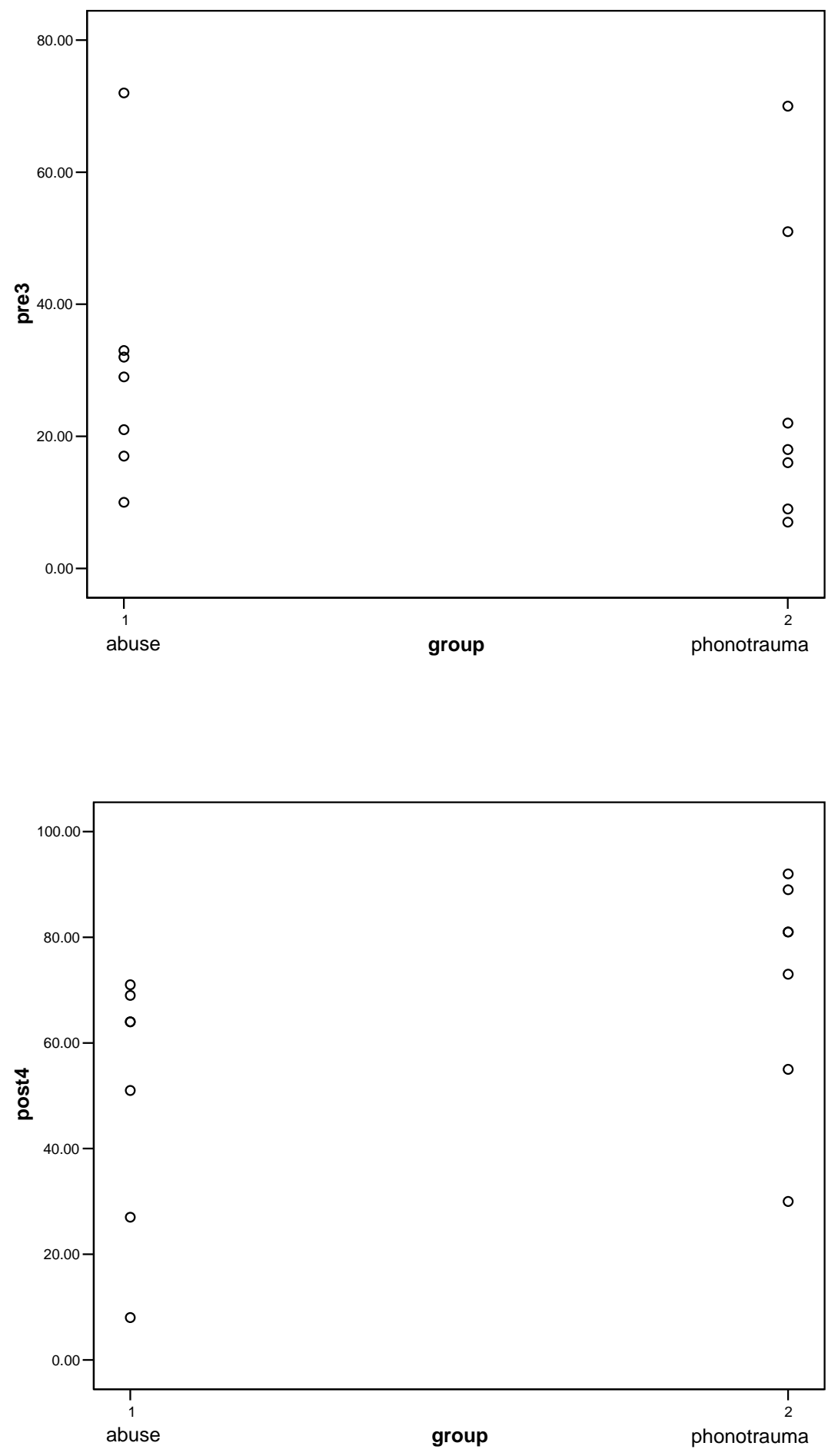

Figure 1 Continued. 
The Influence of Clinical Terminology on Self-Efficacy for Voice

Table 3. Intra-rater reliability. (Pearson $r$ and Interclass Correlation.)

(Question 1: How confident are you in your ability to use your voice effectively?

Question 2: How confident are you in your ability to use your voice in a healthy way?

Question 3: How confident are you in your ability to use your voice without harming it?

Question 4: How confident are you in your ability to change the way you use your voice?)

\begin{tabular}{|c|c|c|c|c|}
\hline & & $\begin{array}{l}\text { Pearson } \\
\mathrm{r}\end{array}$ & $\mathrm{p}$ & ICC \\
\hline \multirow[t]{4}{*}{ Pre } & Question 1 & 1.000 & $<.0001$ & 1.000 \\
\hline & Question 2 & .999 & $<.0001$ & .998 \\
\hline & Question 3 & .992 & $<.0001$ & .992 \\
\hline & Question 4 & .998 & $<.0001$ & .998 \\
\hline \multirow[t]{4}{*}{ Post } & Question 1 & .998 & $<.0001$ & .998 \\
\hline & Question 2 & 1.000 & $<.0001$ & .999 \\
\hline & Question 3 & .990 & $<.0001$ & .990 \\
\hline & Question 4 & .996 & $<.0001$ & .996 \\
\hline
\end{tabular}


The Influence of Clinical Terminology on Self-Efficacy for Voice

Table 4. Paired samples t-test analyzing intra-rater differences.

Paired Samples Statistics

$\begin{array}{llrrrr} & & \text { Mean } & \text { Std. Dev. } \mathrm{t} & \mathrm{p} \\ \text { Pair } & & & & & \\ 1 & \text { pre1_1 } & 57.84615 & 25.8903 & 0 & 1 \\ & \text { pre1_2 } & 57.84615 & 25.98027 & & \\ \text { Pair } & & & & & \\ 2 & \text { pre2_1 } & 30.61538 & 20.35329 & -1 & 0.337049 \\ & \text { pre2_2 } & 30.92308 & 20.06017 & & \\ \text { Pair } & & & & & \\ 3 & \text { pre3_1 } & 29.61538 & 21.94136 & 1.103685 & 0.291371 \\ & \text { pre3_2 } & 28.76923 & 22.42823 & & \end{array}$

Pair

$4 \quad$ pre4_1 $54.84615 \quad 31.29922 \quad 0.433013 \quad 0.672686$ pre4_2 $54.61538 \quad 31.19973$

Pair

$5 \quad$ post1_1 $48.23077 \quad 22.37243 \quad-1.14764 \quad 0.273484$ post1_2 48.6923122 .59567

Pair

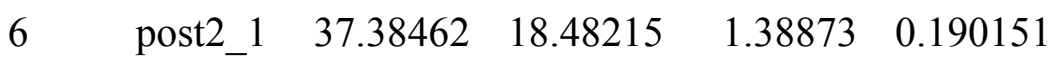
post2_2 $37.15385 \quad 18.80091$

Pair

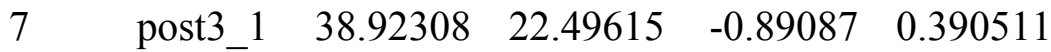
post3_2 $39.69231 \quad 22.14116$

Pair

$8 \quad$ post4_1 $61.53846 \quad 25.64701 \quad-0.57799 \quad 0.573955$ post4_2 $61.92308 \quad 25.91802$ 
The Influence of Clinical Terminology on Self-Efficacy for Voice

Table 5. Test-retest reliability raw data

\begin{tabular}{|c|c|c|c|c|}
\hline Subject & $\begin{array}{l}\text { Question } \\
\text { No. }\end{array}$ & $\begin{array}{l}\text { Reliability pre- } \\
\text { sheet }\end{array}$ & SEQ 1 & $\begin{array}{l}\text { Amt of } \\
\text { change }\end{array}$ \\
\hline B7 & 1 & $\begin{array}{l}\text { Throw out- } \\
\text { outside lines }\end{array}$ & $99 \mathrm{~mm}$ & \\
\hline B8 & & $25 \mathrm{~mm}$ & $19 \mathrm{~mm}$ & $-6 \mathrm{~mm}$ \\
\hline B9 & & $60 \mathrm{~mm}$ & $20 \mathrm{~mm}$ & $-40 \mathrm{~mm}$ \\
\hline A1 & & $83 \mathrm{~mm}$ & $85 \mathrm{~mm}$ & $+2 \mathrm{~mm}$ \\
\hline $\mathrm{A} 2$ & & $32 \mathrm{~mm}$ & $28 \mathrm{~mm}$ & $-4 m m$ \\
\hline A4 & & $65 \mathrm{~mm}$ & $71 \mathrm{~mm}$ & $+6 \mathrm{~mm}$ \\
\hline A6 & & $72 \mathrm{~mm}$ & $84 \mathrm{~mm}$ & $+12 \mathrm{~mm}$ \\
\hline A11 & & $79 \mathrm{~mm}$ & $72 \mathrm{~mm}$ & $-7 \mathrm{~mm}$ \\
\hline A12 & & $69 \mathrm{~mm}$ & $62 \mathrm{~mm}$ & $-7 \mathrm{~mm}$ \\
\hline B7 & 2 & $92 \mathrm{~mm}$ & $52 \mathrm{~mm}$ & $-40 \mathrm{~mm}$ \\
\hline B8 & & $24 \mathrm{~mm}$ & $19 \mathrm{~mm}$ & $-5 \mathrm{~mm}$ \\
\hline B9 & & $51 \mathrm{~mm}$ & $38 \mathrm{~mm}$ & $-13 \mathrm{~mm}$ \\
\hline A1 & & $35 \mathrm{~mm}$ & $11 \mathrm{~mm}$ & $-24 m m$ \\
\hline $\mathrm{A} 2$ & & $29 \mathrm{~mm}$ & $29 \mathrm{~mm}$ & $0 \mathrm{~mm}$ \\
\hline A4 & & $12 \mathrm{~mm}$ & $12 \mathrm{~mm}$ & $0 \mathrm{~mm}$ \\
\hline A6 & & $12 \mathrm{~mm}$ & $21 \mathrm{~mm}$ & $+9 \mathrm{~mm}$ \\
\hline A11 & & $64 \mathrm{~mm}$ & $72 \mathrm{~mm}$ & $+8 \mathrm{~mm}$ \\
\hline A12 & & $37 \mathrm{~mm}$ & $37 \mathrm{~mm}$ & $0 \mathrm{~mm}$ \\
\hline B7 & 3 & $38 \mathrm{~mm}$ & $51 \mathrm{~mm}$ & $+13 \mathrm{~mm}$ \\
\hline B8 & & $24 \mathrm{~mm}$ & $9 \mathrm{~mm}$ & $-15 \mathrm{~mm}$ \\
\hline B9 & & $33 \mathrm{~mm}$ & $22 \mathrm{~mm}$ & $-11 \mathrm{~mm}$ \\
\hline A1 & & $39 \mathrm{~mm}$ & $17 \mathrm{~mm}$ & $-22 \mathrm{~mm}$ \\
\hline $\mathrm{A} 2$ & & $28 \mathrm{~mm}$ & $29 \mathrm{~mm}$ & $+1 \mathrm{~mm}$ \\
\hline A4 & & $10 \mathrm{~mm}$ & $10 \mathrm{~mm}$ & $0 \mathrm{~mm}$ \\
\hline A6 & & $11 \mathrm{~mm}$ & $21 \mathrm{~mm}$ & $+10 \mathrm{~mm}$ \\
\hline A11 & & $63 \mathrm{~mm}$ & $72 \mathrm{~mm}$ & $+9 \mathrm{~mm}$ \\
\hline A12 & & $31 \mathrm{~mm}$ & $33 \mathrm{~mm}$ & $-2 \mathrm{~mm}$ \\
\hline B7 & 4 & $36 \mathrm{~mm}$ & $20 \mathrm{~mm}$ & $-16 \mathrm{~mm}$ \\
\hline B8 & & $73 \mathrm{~mm}$ & $83 \mathrm{~mm}$ & $+10 \mathrm{~mm}$ \\
\hline B9 & & $6 \mathrm{~mm}$ & $5 \mathrm{~mm}$ & $-1 \mathrm{~mm}$ \\
\hline A1 & & $3 \mathrm{~mm}$ & $0 \mathrm{~mm}$ & $-3 \mathrm{~mm}$ \\
\hline A2 & & $76 \mathrm{~mm}$ & $71 \mathrm{~mm}$ & $-5 \mathrm{~mm}$ \\
\hline A4 & & $9 \mathrm{~mm}$ & $8 \mathrm{~mm}$ & $-1 \mathrm{~mm}$ \\
\hline A6 & & $13 \mathrm{~mm}$ & $22 \mathrm{~mm}$ & $+9 \mathrm{~mm}$ \\
\hline A11 & & $50 \mathrm{~mm}$ & $69 \mathrm{~mm}$ & $+19 \mathrm{~mm}$ \\
\hline A12 & & $52 \mathrm{~mm}$ & $56 \mathrm{~mm}$ & $+4 \mathrm{~mm}$ \\
\hline
\end{tabular}


The Influence of Clinical Terminology on Self-Efficacy for Voice

Table 6. Intra-subject (test-retest) reliability. (Pearson Correlation $r$ and Intraclass

Correlation, ICC). (Question 1: How confident are you in your ability to use your voice effectively? Question 2: How confident are you in your ability to use your voice in a healthy way? Question 3: How confident are you in your ability to use your voice without harming it? Question 4: How confident are you in your ability to change the way you use your voice?)

\begin{tabular}{|c|c|c|c|c|}
\hline & $\mathrm{n}$ & $\begin{array}{l}\text { Pearson } \\
r\end{array}$ & $p$ & ICC \\
\hline Question 1 & 8 & 0.84 & 0.009 & 0.806 \\
\hline Question 2 & 9 & 0.787 & 0.012 & 0.745 \\
\hline Question 3 & 9 & 0.809 & 0.008 & 0.801 \\
\hline Question 4 & 9 & 0.952 & $<.0001$ & 0.95 \\
\hline All items together & 35 & 0.865 & $<.0001$ & 0.862 \\
\hline
\end{tabular}


The Influence of Clinical Terminology on Self-Efficacy for Voice

Table 7. Pearson correlations between responses to all questions, and significance 1 evels, based on pre-test.

\section{Correlations}

\begin{tabular}{|ll|r|r|r|r|}
\hline & \multicolumn{1}{|c|}{ pre1 } & \multicolumn{1}{c|}{ pre2 } & \multicolumn{1}{c|}{ pre3 } & \multicolumn{1}{c|}{ pre4 } \\
\hline pre1 & Pearson Correlation & 1 & .279 & .451 & -.498 \\
& Sig. (2-tailed) & & .334 & .105 & .070 \\
& $\mathrm{~N}$ & 14 & 14 & 14 & 14 \\
\hline pre2 & Pearson Correlation & .279 & 1 & $.884^{\star *}$ & .088 \\
& Sig. (2-tailed) & .334 & & .000 & .765 \\
& $\mathrm{~N}$ & 14 & 14 & 14 & 14 \\
\hline pre3 & Pearson Correlation & .451 & $.884^{\star *}$ & 1 & .135 \\
& Sig. (2-tailed) & .105 & .000 & & .646 \\
& $\mathrm{~N}$ & 14 & 14 & 14 & 14 \\
\hline pre4 & Pearson Correlation & -.498 & .088 & .135 & 1 \\
& Sig. (2-tailed) & .070 & .765 & .646 & 14 \\
& $\mathrm{~N}$ & 14 & 14 & 14 & 14 \\
\hline
\end{tabular}

**. Correlation is significant at the 0.01 level (2-tailed). 
The Influence of Clinical Terminology on Self-Efficacy for Voice

Table 8. Individual data: pre- and post-exposure responses to the Voice Self-Efficacy

Questionnaire (in mm). Question 1: How confident are you in your ability to use your

voice effectively? Question 2: How confident are you in your ability to use your voice in a healthy way? Question 3: How confident are you in your ability to use your voice without harming it? Question 4: How confident are you in your ability to change the way you use your voice?

\begin{tabular}{|l|l|l|l|l|l|}
\hline $\begin{array}{l}\text { Q } \\
\text { \# }\end{array}$ & $\begin{array}{l}\text { Group “A” } \\
\text { Abuse/Misuse Condition } \\
\text { Subject \# }\end{array}$ & $\begin{array}{l}\mathbf{m m} \\
\text { Pre }\end{array}$ & $\begin{array}{l}\mathbf{m m} \\
\text { Post }\end{array}$ & $\begin{array}{l}\text { Amt of } \\
\text { Change in } \\
\text { mm }\end{array}$ & $\begin{array}{l}\text { Avg Amount of } \\
\text { Change for Group } \\
\text { in mm }\end{array}$ \\
\hline 1 & 6 & $84 \mathrm{~mm}$ & $83 \mathrm{~mm}$ & $-1 \mathrm{~mm}$ & \\
\hline & 2 & $28 \mathrm{~mm}$ & $27 \mathrm{~mm}$ & $-1 \mathrm{~mm}$ & \\
\hline & 11 & $72 \mathrm{~mm}$ & $68 \mathrm{~mm}$ & $-4 \mathrm{~mm}$ & \\
\hline & 4 & $71 \mathrm{~mm}$ & $69 \mathrm{~mm}$ & $-2 \mathrm{~mm}$ & \\
\hline & 1 & $85 \mathrm{~mm}$ & $44 \mathrm{~mm}$ & -41 & \\
\hline & 15 & $50 \mathrm{~mm}$ & $48 \mathrm{~mm}$ & $-2 \mathrm{~mm}$ & \\
\hline & 12 & $62 \mathrm{~mm}$ & $63 \mathrm{~mm}$ & $+1 \mathrm{~mm}$ & $-50 \mathrm{~mm}$ \\
\hline & & & & & \\
\hline 2 & 6 & $21 \mathrm{~mm}$ & $26 \mathrm{~mm}$ & $+5 \mathrm{~mm}$ & \\
\hline & 2 & $29 \mathrm{~mm}$ & $28 \mathrm{~mm}$ & $-1 \mathrm{~mm}$ & \\
\hline & 11 & $72 \mathrm{~mm}$ & $65 \mathrm{~mm}$ & $-7 \mathrm{~mm}$ & \\
\hline & 4 & $12 \mathrm{~mm}$ & $7 \mathrm{~mm}$ & $-5 \mathrm{~mm}$ & \\
\hline & 1 & $11 \mathrm{~mm}$ & $37 \mathrm{~mm}$ & $+26 \mathrm{~mm}$ & \\
\hline & 15 & $55 \mathrm{~mm}$ & $48 \mathrm{~mm}$ & $-7 \mathrm{~mm}$ & \\
\hline & 12 & $37 \mathrm{~mm}$ & $49 \mathrm{~mm}$ & $+12 \mathrm{~mm}$ & $+23 \mathrm{~mm}$ \\
\hline & & & & & \\
\hline 3 & 6 & $21 \mathrm{~mm}$ & $27 \mathrm{~mm}$ & $+6 \mathrm{~mm}$ & \\
\hline & 2 & $29 \mathrm{~mm}$ & $32 \mathrm{~mm}$ & $+3 \mathrm{~mm}$ & \\
\hline & 11 & $72 \mathrm{~mm}$ & $66 \mathrm{~mm}$ & $-6 \mathrm{~mm}$ & \\
\hline & 4 & $10 \mathrm{~mm}$ & $7 \mathrm{~mm}$ & $-3 \mathrm{~mm}$ & \\
\hline & 1 & $17 \mathrm{~mm}$ & $37 \mathrm{~mm}$ & $+20 \mathrm{~mm}$ & \\
\hline & 15 & $32 \mathrm{~mm}$ & $41 \mathrm{~mm}$ & $+9 \mathrm{~mm}$ & \\
\hline & 12 & $33 \mathrm{~mm}$ & $46 \mathrm{~mm}$ & $+13 \mathrm{~mm}$ & $+42 \mathrm{~mm}$ \\
\hline & & & & & \\
\hline 4 & 6 & $22 \mathrm{~mm}$ & $28 \mathrm{~mm}$ & $+6 \mathrm{~mm}$ & \\
\hline & 2 & $71 \mathrm{~mm}$ & $71 \mathrm{~mm}$ & $0 \mathrm{~mm}$ & \\
\hline & 11 & $69 \mathrm{~mm}$ & $69 \mathrm{~mm}$ & $0 \mathrm{~mm}$ & \\
\hline & 4 & $8 \mathrm{~mm}$ & $8 \mathrm{~mm}$ & $0 \mathrm{~mm}$ & \\
\hline & 1 & $0 \mathrm{~mm}$ & $64 \mathrm{~mm}$ & $+64 \mathrm{~mm}$ & \\
\hline & 15 & $64 \mathrm{~mm}$ & $64 \mathrm{~mm}$ & $0 \mathrm{~mm}$ & \\
\hline & 12 & $56 \mathrm{~mm}$ & $51 \mathrm{~mm}$ & $-5 \mathrm{~mm}$ & \\
\hline-- & -------------- & ------- & -------- & --------------- & -------------------- \\
\hline & & & & & \\
& & & & & \\
\hline & & & & & \\
\hline
\end{tabular}


The Influence of Clinical Terminology on Self-Efficacy for Voice

\begin{tabular}{|l|l|l|l|l|l|}
\hline $\begin{array}{l}\text { Q } \\
\#\end{array}$ & $\begin{array}{l}\text { Group “B” } \\
\text { Phonotrauma Condition } \\
\text { Subject \# }\end{array}$ & $\begin{array}{l}\mathbf{m m} \\
\text { pre }\end{array}$ & $\begin{array}{l}\mathbf{m m} \\
\text { post }\end{array}$ & $\begin{array}{l}\text { Amt of } \\
\text { Change in } \\
\mathbf{m m}\end{array}$ & $\begin{array}{l}\text { Avg Amount of } \\
\text { Change for group } \\
\text { ttl: }\end{array}$ \\
\hline 1 & 8 & $19 \mathrm{~mm}$ & $23 \mathrm{~mm}$ & $+4 \mathrm{~mm}$ & \\
\hline & 7 & $99 \mathrm{~mm}$ & $48 \mathrm{~mm}$ & $-51 \mathrm{~mm}$ & \\
\hline & 5 & $27 \mathrm{~mm}$ & $28 \mathrm{~mm}$ & $+1 \mathrm{~mm}$ & \\
\hline & 13 & $27 \mathrm{~mm}$ & $11 \mathrm{~mm}$ & $-16 \mathrm{~mm}$ & \\
\hline & 3 & $57 \mathrm{~mm}$ & $39 \mathrm{~mm}$ & $-18 \mathrm{~mm}$ & \\
\hline & 11 & $71 \mathrm{~mm}$ & $76 \mathrm{~mm}$ & $+5 \mathrm{~mm}$ & \\
\hline & 9 & $20 \mathrm{~mm}$ & $60 \mathrm{~mm}$ & $+40 \mathrm{~mm}$ & $-35 \mathrm{~mm}$ \\
\hline & & & & & \\
\hline 2 & 8 & $19 \mathrm{~mm}$ & $45 \mathrm{~mm}$ & $+26 \mathrm{~mm}$ & \\
\hline & 7 & $52 \mathrm{~mm}$ & $30 \mathrm{~mm}$ & $-22 \mathrm{~mm}$ & \\
\hline & 5 & $16 \mathrm{~mm}$ & $27 \mathrm{~mm}$ & $+11 \mathrm{~mm}$ & \\
\hline & 13 & $8 \mathrm{~mm}$ & $9 \mathrm{~mm}$ & $+1 \mathrm{~mm}$ & \\
\hline & 3 & $17 \mathrm{~mm}$ & $65 \mathrm{~mm}$ & $+48 \mathrm{~mm}$ & \\
\hline & 11 & $50 \mathrm{~mm}$ & $50 \mathrm{~mm}$ & $0 \mathrm{~mm}$ & \\
\hline & 9 & $38 \mathrm{~mm}$ & $48 \mathrm{~mm}$ & $+10 \mathrm{~mm}$ & $+74 \mathrm{~mm}$ \\
\hline & & & & & \\
\hline 3 & 8 & $9 \mathrm{~mm}$ & $43 \mathrm{~mm}$ & $+34 \mathrm{~mm}$ & \\
\hline & 7 & $51 \mathrm{~mm}$ & $31 \mathrm{~mm}$ & $-20 \mathrm{~mm}$ & \\
\hline & 5 & $18 \mathrm{~mm}$ & $26 \mathrm{~mm}$ & $+8 \mathrm{~mm}$ & \\
\hline & 13 & $7 \mathrm{~mm}$ & $10 \mathrm{~mm}$ & $+3 \mathrm{~mm}$ & \\
\hline & 3 & $16 \mathrm{~mm}$ & $80 \mathrm{~mm}$ & $+64 \mathrm{~mm}$ & \\
\hline & 11 & $70 \mathrm{~mm}$ & $71 \mathrm{~mm}$ & $+1 \mathrm{~mm}$ & \\
\hline & 9 & $22 \mathrm{~mm}$ & $50 \mathrm{~mm}$ & $+28 \mathrm{~mm}$ & $+118 \mathrm{~mm}$ \\
\hline & & & & & \\
\hline 4 & 8 & $83 \mathrm{~mm}$ & $89 \mathrm{~mm}$ & $+6 \mathrm{~mm}$ & \\
\hline & 7 & $20 \mathrm{~mm}$ & $30 \mathrm{~mm}$ & $+10 \mathrm{~mm}$ & \\
\hline & 5 & $97 \mathrm{~mm}$ & $81 \mathrm{~mm}$ & $-16 \mathrm{~mm}$ & \\
\hline & 13 & $74 \mathrm{~mm}$ & $81 \mathrm{~mm}$ & $+7 \mathrm{~mm}$ & \\
\hline & 3 & $73 \mathrm{~mm}$ & $92 \mathrm{~mm}$ & $+19 \mathrm{~mm}$ & \\
\hline & 11 & $76 \mathrm{~mm}$ & $73 \mathrm{~mm}$ & $-3 \mathrm{~mm}$ & \\
\hline & 9 & $5 \mathrm{~mm}$ & $55 \mathrm{~mm}$ & $+50 \mathrm{~mm}$ & $+73 \mathrm{~mm}$ \\
\hline & & & & & \\
\hline
\end{tabular}


The Influence of Clinical Terminology on Self-Efficacy for Voice

Table 9. Results of a t-test to compare groups on pre to post-test change.

\begin{tabular}{llrrrrrr} 
& & \multicolumn{2}{c}{ Std. } & & \multicolumn{2}{c}{$\mathrm{d}$} \\
Question1 & group & Mean & \multicolumn{1}{c}{ Dev. } & $\mathrm{t}$ & $\mathrm{p}$ & & (Eff. Size) \\
& 2 phonotrauma & -0.71 & 0.76 & -1.73 & 0.109 & .65 \\
Question2 & 1 abuse & -0.14 & 1.07 & & & .54 \\
& 2 phonotrauma & 0.57 & 0.79 & & & .43 \\
Question3 & 1 abuse & 0.14 & 1.07 & -1.15 & 0.271 & .23 \\
& 2 phonotrauma & 0.71 & 0.76 & & & \\
Question4 & 1 abuse & 0.14 & 0.69 & -0.63 & 0.539 & .180 \\
& 2 phonotrauma & 0.43 & 0.98 & & &
\end{tabular}


The Influence of Clinical Terminology on Self-Efficacy for Voice

Appendix A

\section{TEXT FOR ABUSE/MISUSE CONDITION}

(Text for presenter only)

$\square$ Hello. I am a speech-language pathologist specialized in the evaluation and treatment of voice disorders. If you have come to this seminar, you are a teacher with concerns about your voice. The purpose of the seminar is to provide you with introductory information about voice problems in teachers, their causes and treatments. Most important, our goal is to direct you to the appropriate health-care professional for evaluation and treatment of your problem. This seminar is not a substitute for professional, one-on-one care.

$\square$ You can follow along with these brief introductory remarks in handouts that have been provided to you.

Voice Disorders in Teachers: Causes and Next Steps

An educational seminar

Amanda Gillespie, BS

Kittie Verdolini, Ph.D., CCC-SLP

Prevalence

$\square$ About 3-9\% of the US population has a voice disorder at any given time

$\square$ Teachers represent about $5.5 \%$ of the employed US population, but represent about $20 \%$ of patients in some voice clinics

$\square \mathrm{Up}$ to about $50 \%$ of teachers report voice problems

$\square$ More than 500,000 seek treatment annually in the US Verdolini \& Ramig, Mattiske et al. 1997.

COST in $\$ \$ \$$

$\square$ Avg. cost/treatment $>\$ 4,000$

$\square$ More than $\$ 2.6$ billion dollars/year in US

$\square$ About $20-30 \%$ of teachers missed work due to voice problems

$\square$ Average \# of work days lost by teachers with voice problems $=8.5$ days

$\square$ Avg. annual cost for substitute teachers $=\sim \$ 1$ billion/yr in US

Verdolini \& Ramig

COST in function

$\square 75 \%$ report moderate or worse negative social effects

$\square 65 \%$ report moderate or worse depression

$\square$ Hoarseness in teachers may reduce cognitive functioning in students (more on this later)

(Morton \& Watson, 2001). 
The Influence of Clinical Terminology on Self-Efficacy for Voice

WHAT?

Voice problems manifest as:

$\square$ Hoarse voice

$\square$ Breathy voice

$\square$ Vocal fatigue

$\square$ Increased effort needed for voicing

$\square$ Loss of high notes

$\square$ Loss of loudness

WHY?

$\square$ Main cause in teachers:

Vocal Abuse/Misuse by the voice user

(that's YOU!)

Why?

$\square$ Other causes:

Dehydration

- Irritants

$\square$ Internal: Laryngopharyngeal reflux

$\square$ External: Inhaled toxins or allergens

Conclusion

$\square$ Control of abuse/misuse

$\square$ Increase hydration, and decrease irritants

should reduce voice problems!!!

Backing Up: The Basics:

$\square$ Phonation/voicing:

Occurs when air from the lungs and trachea exerts pressure on the vocal folds, causing them to vibrate.

The Basics (cont'd)

$\square$ Pitch is increased by lengthening (stretching) or shortening (loosening) the vocal folds (like a stringed instrument- the more taut the string, the higher the note)

The Basics (cont'd)

$\square$ Loudness is increased by (a) using more lung pressure, (b) getting the vocal folds together (but not pressed), or (c) shaping the throat and mouth to amplify the sound.

The Basics (cont'd)

Generally, the system works great! 
However ....

Your role

$\square$ Although many conditions can cause voice problems, if you are a teacher with voice problems, there is strong likelihood that you have abused and/or misused your vocal folds!

Voice Abuse/Misuse

\section{$\square$ Abuse}

Screaming \& yelling

- Talking too much, too loudly

Singing too much, too loudly

\section{$\square$ Misuse}

Talking (or singing) with inefficient technique

Also

$\square$ Not drinking enough water

$\square$ Exposing your vocal mechanism to irritants:

- Smoking

alcohol

Certain drugs

- Toxic environments

Physical Outcomes of

Vocal Abuse/Misuse

Nodules: Bilateral lesions (callouses) on the vocal folds.

$\square$ Usually from multiple abusive events

$\square$ Consequences include hoarse, breathy voice \& reduction in pitch range

$\square$ Treated with voice therapy

$\square$ Sometimes also treated with surgery

Nodules

Physical Outcomes of

Vocal Abuse/Misuse

Polyps: Usually unilateral lesion on the vocal fold

$\square$ Often accompanied by a reactive lesion on the other fold

$\square$ May be sessile (attached) or peduncular (hanging)

$\square$ May develop from a single abusive event, or several discrete events

$\square$ Consequences include hoarseness, breathiness, reduction in pitch range

$\square$ Often treated with voice therapy and surgery

Polyps

Physical Outcomes of

Vocal Abuse/Misuse

Cysts: Unilateral vocal fold lesions

$\square$ May be caused by vocal abuse/misuse in some cases (debated) 
$\square$ Consequences include hoarseness, vocal fatigue, loss of pitch range, loss of very soft and very loud speech capabilities

$\square$ often treated with surgery, and possibly voice therapy supportively Cysts

Physical Outcomes of

Vocal Abuse/Misuse

Edema: Swelling of vocal folds

$\square$ Upper airway illness or reflux, or vocal abuse/misuse

$\square$ Consequences include hoarseness, breathiness, reduction of pitch range

$\square$ Can accompany other previously mentioned pathologies

Edema

WHAT

DO

WE

DO???

What to do?

$\square$ Obtain evaluation and treatment by a competent professional (an otolaryngologist and speech-language pathologist specialized in voice)

E.g. Dr. Clark Rosen (University of Pittsburgh Voice Center, 412-647-7464)

E.g. Dr. Philip Pollice (Allegheny General Hospital, 412-321-1810)

What to do in the meantime

$\square$ 1. You have abused and/or misused your voice.

$\square$ 2. Your vocal technique is not optimal.

$\square$ 3. You must stop abusing and misusing your voice in order to continue efficiently speaking and teaching.

What to do in the meantime

2. Minimize reflux

Avoid:

$\square$ Eating late

$\square$ Spicy foods, caffeine, chocolate, tomatoes and other acidic-based foods and drinks

What to do in the meantime

3. Minimize environmental factors

Avoid:

$\square$ Smoking

DExcessive alcohol consumption

DInhaling chemicals or other irritants (household, industrial, allergic, etc.)

DDehydration (DRINK A LOT OF WATER!!!! Use a humidifier, steam inhaler) MOST IMPORTANT!

$\square$ If you think you may have a voice disorder, make an appointment with a specialized otolaryngologist and speech language pathologist for evaluation and treatment ASAP! 
The Influence of Clinical Terminology on Self-Efficacy for Voice

$\square$ The longer you abuse and/or misuse your voice, the more damage you will do! STOP THE ABUSE!

$\square$ You have been abusing and/or misusing your voice. You must avoid these behaviors to safeguard your voice for the future! 
The Influence of Clinical Terminology on Self-Efficacy for Voice

Appendix B

\section{TEXT FOR PHONOTRAUMA/MUSCLE TENSION CONDITION}

(Text for presenter only)

$\square$ Hello. I am a speech-language pathologist specialized in the evaluation and treatment of voice disorders. If you have come to this seminar, you are a teacher with concerns about your voice. The purpose of the seminar is to provide you with introductory information about voice problems in teachers, their causes and treatments. Most important, our goal is to direct you to the appropriate health-care professional for evaluation and treatment of your problem. This seminar is not a substitute for professional, one-on-one care.

$\square$ You can follow along with these brief introductory remarks in handouts that have been provided to you.

Voice Disorders in Teachers: Causes and Next Steps

An educational seminar

Amanda Gillespie, BS

Kittie Verdolini, Ph.D., CCC-SLP

Prevalence

$\square$ About 3-9\% of the US population has a voice disorder at any given time

$\square$ Teachers represent about $5.5 \%$ of the employed US population, but represent about $20 \%$ of patients in some voice clinics

$\square \mathrm{Up}$ to about $50 \%$ of teachers report voice problems

$\square$ More than 500,000 seek treatment annually in the US

Verdolini \& Ramig; Mattiske et al. 1997

COST in $\$ \$ \$$

$\square$ Avg. cost/treatment $>\$ 4,000$

$\square$ More than $\$ 2.6$ billion dollars/year in US

$\square$ About $20-30 \%$ of teachers missed work due to voice problems

$\square$ Average \# of work days lost by teachers with voice problems $=8.5$ days

$\square$ Avg. annual cost for substitute teachers $=\sim \$ 1$ billion/yr in US 
The Influence of Clinical Terminology on Self-Efficacy for Voice

Verdolini \& Ramig

COST in function

$\square 75 \%$ report moderate or worse negative social effects

$\square 65 \%$ report moderate or worse depression

$\square$ Hoarseness in teachers may reduce cognitive functioning in students (more on this later)

(Morton \& Watson, 2001).

\section{WHAT?}

Voice problems manifest as:

$\square$ Hoarse voice

$\square$ Breathy voice

$\square$ Vocal fatigue

$\square$ Increased effort needed for voicing

$\square$ Loss of high notes

$\square$ Loss of loudness

WHY?

$\square$ Main cause in teachers:

\section{Phonotrauma}

and

Muscle Tension

Why?

$\square$ Other causes:

Dehydration

- Irritants

$\square$ Internal: Laryngopharyngeal reflux

$\square$ External: Inhaled toxins or allergens

Conclusion

$\square$ Control of phonotrauma, muscle tension

$\square$ Control of dehydration and irritants

should reduce voice problems!!!

Backing Up: The Basics:

$\square$ Phonation/voicing:

Occurs when air from the lungs and trachea exerts pressure on the vocal folds, causing them to vibrate.

The Basics (cont'd) 
$\square$ Pitch is increased by lengthening (stretching) or shortening (loosening) the vocal folds (like a stringed instrument- the more taut the string, the higher the note)

The Basics (cont'd)

$\square$ Loudness is increased by (a) using more lung pressure, (b) getting the vocal folds together (but not pressed), or (c) shaping the throat and mouth to amplify the sound.

The Basics (cont'd)

Generally, the system works great!

\section{However ....}

Your role

$\square$ Although many conditions can cause voice problems, if you are a teacher with voice problems, there is strong likelihood that you have incurred phonotrauma to your vocal folds, or have muscle tension.

Phonotrauma and Muscle Tension

\section{$\square$ Phonotrauma:}

Pressing the vocal folds together too tightly in voicing

-High pitch within a given register

U Using too much lung pressure in voice

\section{$\square$ Muscle tension:}

Usually in the head and neck

Also

$\square$ Not drinking enough water

$\square$ Exposing your vocal mechanism to irritants:

- Smoking

-Alcohol

aCertain drugs

- Toxic environments

Physical Outcomes of

Phonotrauma

Nodules: Bilateral lesions (callouses) on the vocal folds.

$\square$ Usually from multiple phonotraumatic events

$\square$ Consequences include hoarse, breathy voice \& reduction in pitch range

$\square$ Treated with voice therapy

$\square$ Sometimes also treated with surgery

Nodules

Physical Outcomes of

Phonotrauma 
Polyps: Usually unilateral lesion on the vocal fold

$\square$ Often accompanied by a reactive lesion on the other fold

$\square$ May be sessile (attached) or peduncular (hanging)

$\square$ May develop from a single phonotraumatic event, or several discrete events

$\square$ Consequences include hoarseness, breathiness, reduction in pitch range

$\square$ Often treated with voice therapy and surgery

Polyps

Physical Outcomes of

Phonotrauma

Cysts: Unilateral vocal fold lesions

$\square$ May be caused by phonotrauma in some cases (debated)

$\square$ Consequences include hoarseness, vocal fatigue, loss of pitch range, loss of very soft and very loud speech capabilities

$\square$ Often treated with surgery, and possibly voice therapy supportively

Cysts

Physical Outcomes of

Phonotrauma

Edema: Swelling of vocal folds

$\square$ Upper airway illness or reflux, or phonotrauma

$\square$ Consequences include hoarseness, breathiness, reduction of pitch range

$\square$ Can accompany other previously mentioned pathologies

Edema

WHAT

DO

WE

DO???

What to do?

$\square$ obtain evaluation and treatment by a competent professional (an otolaryngologist and speech-language pathologist specialized in voice)

E.g. Dr. Clark Rosen (University of Pittsburgh Voice Center 412-647-7464)

E.g. Dr. Philip Pollice (Allegheny General Hospital, 412-321-1810)

What to do in the meantime

$\square$ 1. You have experienced phonotrauma to your vocal folds

$\square$ 2. As a teacher you are at high risk for voice problems, an occupational risk.

$\square 3$. If you are still teaching, you must be quite good at managing your voice. You can learn voice techniques that should help you minimize problems in the future

What to do in the meantime

2. Minimize reflux

Avoid:

$\square$ Eating late

$\square$ Spicy foods, caffeine, chocolate, tomatoes and other acidic-based foods and drinks 
The Influence of Clinical Terminology on Self-Efficacy for Voice

What to do in the meantime

3. Minimize environmental factors

Avoid:

$\square$ Smoking

$\square$ Excessive alcohol consumption

$\square$ Inhaling chemicals or other irritants (household, industrial, allergic, etc.)

$\square$ Dehydration (DRINK A LOT OF WATER!!!! Use a humidifier, steam inhaler) MOST IMPORTANT!

$\square$ If you think you may have a voice disorder, make an appointment with a specialized otolaryngologist and speech language pathologist for evaluation and treatment ASAP!

$\square$ The less your vocal folds incur phonotrauma, the better your voice will become.

SEEK ASSISTANCE!

$\square$ Seeking professional evaluation and treatment now may help to minimize your risk in the future! 